\title{
Toxicity of Zero- and One-Dimensional Carbon Nanomaterials
}

\author{
Iruthayapandi Selestin Raja ${ }^{1,+}$, Su-Jin Song ${ }^{2,+}$, Moon Sung Kang ${ }^{2}$, Yu Bin Lee ${ }^{2}$, Bongju Kim ${ }^{3}{ }^{(D}$, \\ Suck Won Hong ${ }^{2}{ }^{\circ}$, Seung Jo Jeong ${ }^{4}$, Jae-Chang Lee ${ }^{5, *}$ and Dong-Wook Han ${ }^{2, *}$ \\ 1 Monocrystalline Bank Research Institute, Pusan National University, Busan 46241, Korea \\ 2 Department of Cogno-Mechatronics Engineering, College of Nanoscience \& Nanotechnology, Pusan \\ National University, Busan 46241, Korea \\ 3 Dental Life Science Research Institute \& Clinical Translational Research Center for Dental Science, Seoul \\ National University Dental Hospital, Seoul 03080, Korea \\ 4 GS Medical Co., Ltd., Cheongju-si, Chungcheongbuk-do 28161, Korea \\ 5 Bio-Based Chemistry Research Center, Korea Research Institute of Chemical Technology, Ulsan 44429, Korea \\ * Correspondence: jclee@krict.re.kr (J.-C.L.); nanohan@pusan.ac.kr (D.-W.H.) \\ + These authors contributed equally to this work.
}

Received: 5 August 2019; Accepted: 23 August 2019; Published: 28 August 2019

check for updates

\begin{abstract}
The zero (0-D) and one-dimensional (1-D) carbon nanomaterials have gained attention among researchers because they exhibit a larger surface area to volume ratio, and a smaller size. Furthermore, carbon is ubiquitously present in all living organisms. However, toxicity is a major concern while utilizing carbon nanomaterials for biomedical applications such as drug delivery, biosensing, and tissue regeneration. In the present review, we have summarized some of the recent findings of cellular and animal level toxicity studies of 0-D (carbon quantum dot, graphene quantum dot, nanodiamond, and carbon black) and 1-D (single-walled and multi-walled carbon nanotubes) carbon nanomaterials. The in vitro toxicity of carbon nanomaterials was exemplified in normal and cancer cell lines including fibroblasts, osteoblasts, macrophages, epithelial and endothelial cells of different sources. Similarly, the in vivo studies were illustrated in several animal species such as rats, mice, zebrafish, planktons and, guinea pigs, at various concentrations, route of administrations and exposure of nanoparticles. In addition, we have described the unique properties and commercial usage, as well as the similarities and differences among the nanoparticles. The aim of the current review is not only to signify the importance of studying the toxicity of 0-D and 1-D carbon nanomaterials, but also to emphasize the perspectives, future challenges and possible directions in the field.
\end{abstract}

Keywords: carbon nanomaterials; unique properties; biomedical applications; in vitro toxicity; in vivo toxicity

\section{Introduction}

Nanotechnology has been a rapidly developing field, producing many nanomaterials with alterations in different physical and physicochemical properties such as size, shape, crystalline nature, and interaction with biological systems [1-3]. These materials have found adaptability in biomedical applications such as nanomedicines, cosmetics, bioelectronics, biosensors, and biochips [4]. However, the fact that possible health risks are associated with the increasing development of nanotechnology cannot be set aside. Nanoparticles may be either organic or inorganic based on the composition of elements. Mostly, inorganic nanomaterials are based on transition metals such as silver, iron, gold, zinc, copper, etc. whereas carbon nanomaterials are mainly composed of the carbon element, which constitutes various spatial arrangements in different nanoscales from zero (0-D) to three dimensions 
(3-D) [1,5-7]. In the present review, we will discuss the toxicity of 0-D carbon nanostructures (carbon black, nanodiamond, carbon nanodots and fullerene) and 1-D nanomaterials (single and multi-walled carbon nanotubes) from the research that has been conducted over the past two decades. The structure of carbon nanomaterials is shown in Figure 1.

Carbon dots are carbon-based nanomaterials with unique properties such as chemical inertness, optical stability, and wavelength-dependent photoluminescence [8]. Carbon quantum dots (CQDs) are typically quasi-spherical nanoparticles with a diameter less than $10 \mathrm{~nm}$ and composed of carbon, oxygen, hydrogen, nitrogen, and other elements. Because of their hydrophilic nature and cell permeation, CQDs have replaced traditional metal-based quantum dots in many applications, including photovoltaics, photocatalysis, and drug targeting [9]. The oxidized CQDs may contain 5-50\% oxygen depending on synthetic procedures. Carbon quantum dots typically present two optical absorption bands in the UV-vis spectrum, which are attributed to $\pi-\pi^{*}$ and $n-\pi^{*}$ transitions in $\mathrm{C}=\mathrm{C}$ and $\mathrm{C}=\mathrm{O}$ bonds, respectively [10]. When the carbon nanodots are represented as a $\pi$-conjugated single sheet, with a size of $2-10 \mathrm{~nm}$, they are called graphene quantum dots [11]. It has been reported that graphene quantum dots (GQDs) exhibit magnetic, electronic, and optical properties [12].

Nanodiamonds (NDs) are carbon-based crystalline nanoparticles inheriting diamond structure at the nanoscale with excellent properties such as optical transparency, hardness and chemical inertness [13]. The $\mathrm{sp}^{3}$ tetrahedral structure of the nanodiamond presents Raman signal at $1332 \mathrm{~cm}^{-1}$ and is capable of fluorescing due to point defects. However, the non-fluorescing nanodiamond displays a strong coherent anti-Stokes Raman scattering effect [14]. The quantitative analysis of cellular uptake of NDs is promising for the applications of bio labeling and bio imaging. The oxidized form of the nanodiamond has been reported to damage DNA in embryonic stem cells [15].

Carbon black nanoparticles (CBNPs) are the zero-dimensional carbon-based nanomaterials, which are produced in large quantities in different ways, such as partial combustion and thermal decomposition of hydrocarbons either in liquid or gaseous state [16]. The poor water-soluble carbon black poses a threat to health when exposed to the lungs through inhalation. The core portion of the insoluble particle yields reactive oxygen species (ROS), which render toxicity to the experimental animals [17]. Recently, the International Agency for Research on Cancer (IARC) listed carbon black nanoparticles as carcinogenic to human beings [16]. In toxicological studies, carbon black nanoparticles (CBNPs), with diameters less than $100 \mathrm{~nm}$, have been reference material for diesel exhaust particles [18]. The aciniform aggregates of carbon black are basically fine powder in the size range of 100-1000 nm in a closed reaction chamber and form larger agglomerates due to van der Waals forces in the final step of the manufacturing process [19]. The term 'carbon black' should not be confused with such words as black carbon and soot, which are the carbonaceous materials emitted from incomplete combustion of fuels, such as waste oil, diesel, gasoline, wood, paper, plastic and rubber [20]. It is important to note that carbon black nanoparticles have certain physicochemical properties in common with another insoluble carbonaceous material, including graphene [16]. CBNPs have been widely used as conductive fillers due to their low aspect ratio, being economically inexpensive, and having good conductivity [21,22].

Among the carbon-based nanomaterials, fullerene (C60) is a generic term for a cluster composed of 60 carbon atoms that appears as a soccer-ball structure. The C60 contains 30 carbon atoms to readily interact with free radicals, and therefore is known as a free radical sponge $[23,24]$. The versatile applications of C60 include use in superconducting devices, energy device materials and catalysts [25]. The water-soluble polyhydroxylated fullerene, known as fullerenol $(\mathrm{C} 60(\mathrm{OH}) \mathrm{n})$, has been explored for its potential as being an anticancer, anti-HIV and skin rejuvenating cosmetic $[25,26]$. Fullerenol was reported to protect experimental animals from hepatotoxicity and doxorubicin-induced cardiotoxicity [26,27]. In nature, fullerene is available as its analogues including C70, C80, and C94, because of its tendency to aggregate and form a crystal-like structure with a diameter of $100 \mathrm{~nm}$ [23]. The research studies revealed that skin contact and nasal inhalation are the most likely routes of exposure to fullerenes for the workers in industries [25]. 


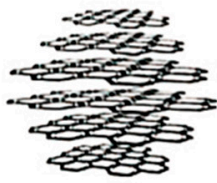

CQD

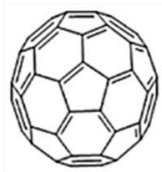

C60

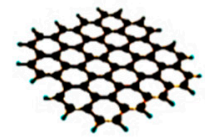

GQD

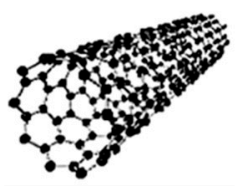

SWCNT

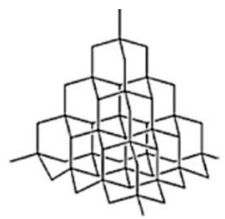

ND

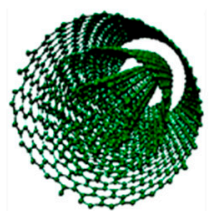

MWCNT

Figure 1. The structure of zero- and one-dimensional carbon nanomaterials have been shown. Carbon quantum dot (CQD) and graphene quantum dot (GQD), reproduced with permission from [11], Copyright Royal Society of Chemistry, 2010; nanodiamond (ND) and fullerene (C60), reproduced with permission from [7], Copyright American Chemical Society, 2013; carbon black nanoparticle (CBNP), reproduced with permission from [28], Copyright Elsevier, 2014; single-walled carbon nanotube (SWCNT) and multi-walled carbon nanotube (MWCNT), reproduced with permission from [29], Copyright Elsevier, 2017.

The unique property of CNT is its high aspect ratio, which promotes its superior properties to the encapsulating matrix polymers and has advantages over traditional reinforcements [30]. The most widely used techniques for the synthesis of carbon nanotubes (CNTs) are laser furnace, chemical vapor deposition, and arc discharge [31]. Their biomedical applications include biosensors, orthopedic prostheses, anticancer therapy, and tissue engineering [32]. The literature reports reveal that maternal exposure of CNTs might develop developmental toxicity such as teratogenicity [33]. The threat of nanotoxicity of CNTs is an increasing trend, as the global production of CNTs reaches several thousand tons per year [32]. Based on morphology, the carbon nanotube is generally classified into the two viz. single-walled and multi-walled carbon nanotubes. When one or several graphene sheets are rolled up to a cylindrical form concentrically, they yield single-walled carbon nanotubes (SWCNTs) and multi-walled carbon nanotubes (MWCNTs), respectively. Meanwhile, MWCNTs differ from SWCNTs in some physicochemical properties, such as the number of layers, the surface area and width $[34,35]$. The preparation of both CNTs also varies with different experimental conditions. For example, in the electric arc discharge method, SWCNTs are synthesized in the form of soot when a graphite rod comprising a metal catalyst acts as an anode and pure graphite as a cathode. Meanwhile, the production of MWCNTs is achieved strictly in the presence of inert gas such as helium. In the laser vaporization method, generation of SWCNTs mainly depends on the type of metal catalyst and the furnace temperature, whereas the yield of MWCNTs requires a pure graphite target and an optimum temperature of $1200{ }^{\circ} \mathrm{C}$ [36]. The nanotubes strongly interact with each other by van der Waals forces and hence exhibit hydrophobicity, which limits their biomedical applications. Hypochlorite, myeloperoxidase, and eosinophils peroxidase have been reported to degrade nanotubes within phagosomes and in the inflammation sites [37]. Researchers have adopted different approaches to modify pristine CNTs to impart hydrophilic behavior. The $\pi$-conjugated skeleton of CNT was covalently modified through different chemical reactions such as sidewall halogenation, hydrogenation, plasma activation, cycloaddition, radical, nucleophilic and electrophilic additions. The non-covalent modification occurs by physical attachment of various functional molecules and the endohedral filling takes place at the inner empty cavity of CNT [38].

SWCNTs have been used in a wide range of commercial applications such as earthquake-resistant buildings, dent-resistant car bodies, stain-resistant textiles and transistors [39]. The diameter of 
SWCNTs is approximately $1-2 \mathrm{~nm}$ and their toxicity is more substantial in comparison to MWCNTs $(10-20 \mathrm{~nm})$ and other carbonaceous nanomaterials such as carbon black and fullerene [40]. Despite being an attractive structural material with a high aspect ratio of length to width, carbon nanotubes threaten living organisms with potentially hazardous effects [41]. As far as the drug administration of SWCNTs is concerned, the inhalation route of exposure has more serious effects than the aspiration route in terms of oxidative stress, inflammatory responses, fibrosis and collagen deposition [42]. It has been reported that the agglomerates of SWCNTs caused granulomas in the proximal alveoli, and dispersed SWCNTs instigated interstitial fibrosis in the distal alveoli [43]. Similar to asbestos, MWCNTs have been reported to possess pathogenicity, owing to their larger durability and needle-like shape [32]. They found a wide variety of industrial applications in rechargeable batteries, water filters and sporting goods [44]. It was informed that non-branched MWCNTs had a higher potential to cause mesothelioma than the tangled MWCNTs [45].

\section{In Vitro Cellular Toxicity of Zero- and One-Dimensional Carbon Nanomaterials}

The in vitro toxicity effects of carbon nanomaterials (0-D and 1-D) have been listed in Table 1. The cytotoxic effect of the polyethylenimine (PEI) coated CQDs based nanohybrid, with a diameter of $6.5 \pm 2 \mathrm{~nm}$, was investigated at various concentrations (200, 400, 600 and $800 \mu \mathrm{g} / \mathrm{mL}$ ) on kidney epithelial cells derived from the African green monkey. The MTT (3-(4,5-dimethylthiazol-2-yl)-2,5-diphenyltetrazolium bromide) assay revealed that the nanohybrid killed $39 \%$ of cells at concentration $600 \mu \mathrm{g} / \mathrm{mL}$, despite there being no sign of significant toxicity at lower concentrations [46]. The pristine fluorescent carbon quantum dots $(\sim 7 \mathrm{~nm})$ were evaluated for its cytotoxicity assessing total ROS, glutathione, and lactate dehydrogenase activity on human bronchial epithelial cells (16 HBE). The data revealed that CQDs preferentially located on the surface of cells and that its exposure induced oxidative stress and decreased cell viability [47]. A comprehensive study was presented to describe the critical role of functionalized nanoparticles in cytotoxicity using mouse embryonic fibroblasts (NIH-3T3). The CQDs synthesized from candle soot were negatively charged. The pristine CQDs were then functionalized with PEG (polyethylene glycol) and PEI to impart neutral and positive charges on the surface of nanoparticles, respectively. The results of in vitro cellular toxicity measurements revealed that the neutral charged CQDs did not induce any abnormalities in the cell cycle, cellular trafficking and cell morphology up to the concentrations of $300 \mu \mathrm{g} / \mathrm{mL}$. Meanwhile, the negatively charged pristine CQDs arrested the cell cycle at the G2/M phase, enhanced cell proliferation, and caused oxidative stress. Being the most cytotoxic, the positively charged CQDs triggered a significant alteration in the cell cycle at the G0/G1 phase, at a concentration of $100 \mu \mathrm{g} / \mathrm{mL}$ [48].

GQDs have also shown different cellular uptake in MC3T3 osteoblast cell lines derived from mouse calvaria and exhibited low cytotoxicity due to their small size and high oxygen content [49]. The adverse effects of hydroxyl-modified GQDs (OH-GQDs) were studied on human lung carcinoma cell lines H1299 and A549. The OH-GQDs with hydrodynamic diameter of $10.3 \pm 1.9 \mathrm{~nm}$, at a concentration $50 \mu \mathrm{g} / \mathrm{mL}$, decreased cell viability and intracellular ROS generation at a significant level. The cell signaling pathway analysis exposed that hydroxylated GQDs induced G0/G1 arrest, cell senescence, and inhibition of $\mathrm{Rb}$ phosphorylation in both types of cells [50]. It was confirmed that GQDs were less cytotoxic to human breast cancer (MCF-7) and human gastric cancer (MGC-803) cells on prolonged incubation. The nanoparticles significantly permeated into both cytoplasm and nucleus of the cells following caveolae-mediated endocytosis, but they did not affect cellular morphology. In addition, the nanoparticles exhibited lower cytotoxicity to MGC-803 cells when compared to MCF-7 cells [51].

Genotoxicity of NDs was analyzed on mouse embryonic stem cells and the results revealed that NDs of 4-5 nm expressed an elevated level of DNA repair proteins such as p53 and MOGG-1. Further, oxidized NDs were described to have more influence on triggering DNA damage than the pristine NDs. However, it was demonstrated that NDs, either in oxidized form or pristine, were not severe in toxicity when compared to MWCNTs [52]. Intracellular ROS, mitochondrial activity, apoptosis, colony formation, and cellular uptake were studied to provide elucidative information 
about the toxicity of NDs in two different cell lines HaCaT and A549. At concentration of $1.0 \mathrm{mg} / \mathrm{mL}$, inhibition of colony formation and small degree apoptosis were observed in cells. However, it was found that NDs did not have any significant influence on cell viability and ROS production [53]. Treated with RAW 264.7 murine macrophages, the cytotoxicity of NDs were examined in various sizes $(6-500 \mathrm{~nm})$ and concentrations $(0-200 \mu \mathrm{g} / \mathrm{mL})$. Cell proliferation and metabolic activity were found reduced in a concentration dependent manner. Flow cytometry analysis revealed that the nanoparticles caused necrosis, leading to significant cytotoxicity, irrespective of particle size [54]. In vitro toxicity measurements were carried out in human blood cells and the reports exposed that NDs could change the kinetics of active oxygen production, cause erythrocyte hemolysis and destruct white cells [55].

The in vitro genotoxic and mutagenic potential of NDs were investigated in human lymphocytes and the nanoparticles were reported to inhibit cell proliferation-inducing apoptotic cell death above $50 \mu \mathrm{g} / \mathrm{mL}$. The cellular oxidative stress generated by the nanoparticles was found to be dose-dependent. Significant changes in chromatin stability followed by DNA oxidative damage were established, even at a concentration of $1 \mu \mathrm{g} / \mathrm{mL}$. NDs had the potential to stimulate micronuclei augmenting centromeric signals at $10 \mu \mathrm{g} / \mathrm{mL}$ [56]. The viability of human umbilical vein endothelial cells (HUVEC-ST) was investigated following the treatment of NDs, which was synthesized by the detonation method. The results of the MTT assay revealed that NDs showed a concentration-dependent cytotoxicity and ROS production in cells [57]. In a study, the cytotoxicity effect of nanodiamond particles was explored by correlating different surface functional groups on the nanoparticles, such as $-\mathrm{OH},-\mathrm{COOH}$ and $-\mathrm{NH}_{2}$. It was shown that NDs were cytotoxic to HEK293 cells when the concentration was above $50 \mu \mathrm{g} / \mathrm{mL}$. The cationic nanodiamond had the potential to permeate negatively charged cell membrane and hence exhibited cytotoxicity. In addition, carboxylated nanodiamond (ND-COOH) was reported to possess embryotoxicity as well as teratogenicity [58].

The in vitro toxicity effect of CBNPs $(260 \pm 13.7 \mathrm{~nm})$ was evaluated on A549 human alveolar basal epithelial cells and suggested that ultrafine particles induced a greater oxidative stress with prolonged inhibitory effects than fine particles [59]. Printex 90, a commercial name of carbon black nanoparticles with a diameter of $14 \mathrm{~nm}$, exhibited an oxidative damage response in HepG2 cells at $25 \mathrm{mg} / \mathrm{L}$, which was revealed from formamidopyrimidine DNA glycosylase (Fpg)-modified comet assay [60]. In another comet (Fpg) assay, it was discovered that an increased level of oxidized purines was observed when the nanoparticles were investigated in the FE1-MML Muta Mouse lung epithelial cell line. The mutant frequency was noticed in carbon black exposed cells following eight repeated $72 \mathrm{~h}$ incubations with a cumulative dose of $6 \mathrm{mg}$ nanoparticles [61]. The western blot analysis exposed that ultrafine carbon black nanoparticles, at $30.7 \mu \mathrm{g} / \mathrm{cm}^{2}$, stimulated proliferation of human primary bronchial epithelial cells through oxidative stress and epidermal growth factor-mediated signaling pathway [62]. The cytotoxic and genotoxic effects of CBNPs were investigated on the mouse macrophage cell line RAW 264.7. The particle size and specific surface area was $14 \mathrm{~nm}$ and $300 \mathrm{~m}^{2} / \mathrm{g}$, respectively. The data confirmed acentric chromosome fragments at all concentrations and there was a slight increase in micronuclei frequencies at 3 and $10 \mathrm{mg} / \mathrm{L}$ [63]. It was reported that CBNPs $(100 \mu \mathrm{g} / \mathrm{mL})$ could induce DNA single-strand breaks and induce AP-1 and NFKB DNA binding in A549 lung epithelial cell line after $3 \mathrm{~h}$ of exposure [64]. The toxicity measurements of CBNPs in THP-1 derived monocytes and macrophages exemplified that the nanoparticles supported endothelial activation and lipid accumulation in THP-1 derived macrophages. In addition, the nanoparticles influenced increased cytotoxicity, LDH levels and intracellular ROS production in a dose-dependent manner [65].

It was discovered that C60 fullerene of approximately $0.7 \mathrm{~nm}$ was less toxic than carbon black and diesel exhaust particles when FE1-MutaMouse lung epithelial cells were exposed to nanoparticles. The results of the comet assay revealed that C60 significantly increased the quantity of formamidopyrimidine-glycosylase sites $(22 \%)$ and oxidized purines $(5 \%)$, though the nanoparticles did not involve breaking DNA strands [66]. Genotoxic effects of C60 sized $0.7 \mathrm{~nm}$ were investigated by micronuclei test in the human lung cancer cell line (A549) at a concentration range of $0.02-200 \mu \mathrm{g} / \mathrm{mL}$ and increased micronuclei frequencies were observed in nanoparticles treated cells in a dose-dependent 
manner [67]. The genotoxic studies of colloidal C60 in human lymphocytes had shown genotoxicity at $2.2 \mu \mathrm{g} / \mathrm{L}$, whereas the ethanolic solution of $\mathrm{C} 60$ had exhibited the same at $0.42 \mu \mathrm{g} / \mathrm{L}$ [68]. The polyhydroxylated C60 fullerenol presented a dose-dependent decrease in micronuclei frequency and chromosome aberration when the nanoparticles were treated with Chinese hamster ovary cells (CHO K1). However, the study did not show any genotoxic effects in the concentrations of 11-221 $\mu \mathrm{m}$ [27]. The cytotoxicity of hydroxylated fullerene was analyzed in vascular endothelial cells at different concentrations, $1-100 \mu \mathrm{g} / \mathrm{mL}$, and a dose-dependent decrease in cell viability was perceived. Furthermore, it was reported that fullerenes affected cell growth and cell attachment with the potential to cause cardiovascular disease after a long period of exposure (10 days) [69].

The toxicity effect of SWCNTs was explored on human embryonic kidney cells (HEK293T) and reported that the nanoparticle exposure resulted in a decrease in cell adhesion, inhibition in cell proliferation and induction in apoptosis, depending on the dosage and time. In addition, a nodular structure was formed due to the nanoparticle aggregation and overlap of cells [70]. The agglomeration of CNTs had a larger impact on triggering cellular toxicity in human MSTO-211H cells. It was found that the agglomerated CNTs were more toxic compared to monodispersed CNTs [71]. The geometric structure of the nanoparticles played a pivotal role in determining cytotoxicity. A comparative study was provided in describing cytotoxicity of SWCNTs, MWCNTs, and C60 fullerenes on guinea pig alveolar macrophages. The order of displaying toxicity was as follows, SWCNTs $>$ MWCNTs $>$ C60 fullerenes [72]. The intracellular distribution of functionalized SWCNTs was studied in murine 3T3 and human 3 T6 fibroblast cells. The length of the nanotube varied from 300 to $1000 \mathrm{~nm}$ and the outer diameter was $1 \mathrm{~nm}$. The analyses revealed that SWCNTs resided either in the cytoplasm or nucleus after crossing the cell membrane, and exhibited toxicity when the concentration of nanoparticles reached above $10 \mu \mathrm{M}$ [73]. It was confirmed that exposure of SWCNTs induced cutaneous and pulmonary toxicities in human bronchial epithelial cells (BEAS-2B) and human keratinocyte cells $(\mathrm{HaCaT})$. The microarray analysis revealed that the nanoparticles triggered alteration of genes followed by transcriptional responses. Cellular morphology, integrity and ultrastructure were affected as the nanoparticles depleted antioxidants in the cells [74,75]. Functionalization of the nanoparticles had taken advantage of reducing the toxic level of nanoparticles. The derivatized SWCNTs were reported to have fewer toxic effects than pristine SWCNTs from in vitro cytotoxicity measurements in human dermal fibroblasts [76]. The introduction of SWCNTs into normal and malignant human mesothelial cells produced ROS causing cell death, DNA damage and H2AX phosphorylation [77]. It was reported that SWCNTs, with a primary particle size of $0.4-1.2 \mathrm{~nm}$ and specific surface area of $26 \mathrm{~m}^{2} / \mathrm{g}$, had the potential to induce DNA damage in lung V79 fibroblasts [78].

The cytotoxic and genotoxic effects of single and multi-walled CNTs were studied on the mouse macrophage cell line RAW 264.7, and it was demonstrated that the exposure of nanoparticles stimulated ROS release, chromosomal aberrations, necrosis, and apoptosis, but they did not cause any inflammatory responses. In addition, MWCNTs were reported to penetrate the cell membrane and reside in the nuclear envelope [63]. Electron microscopic studies indicated that highly purified MWCNTs expressed higher cytotoxic effects by damaging the plasma membrane of mouse macrophages (J774.1). It was found that the cytotoxicity of MWCNTs was significantly larger than crocidolite, a fibrous form of sodium iron silicate [79]. The higher concentrated MWCNTs caused a decrease in cellular viability and an increase in inflammation on prolonged exposure to human epidermal keratinocytes (HEK) cells. The nanoparticles had the potential to penetrate the cell membrane and change the expression level of various proteins. The nanoparticles were reported to be abundantly present within cytoplasmic vacuoles of the cells after cell permeation [80]. The toxicity of MWCNTs of approximately $30 \mathrm{~nm}$ was evaluated in human skin fibroblasts (HSF42) and the results revealed that the nanoparticles disrupted intracellular signaling pathways, causing an increase in apoptosis and necrosis, and activated the genes associated with cellular cycle regulation, metabolism, cellular transport, and stress response [81]. Interestingly, oxidized MWCNTs were described to exhibit more toxicity than pristine MWCNTs. Both were reported to induce apoptosis in T lymphocytes depending on the time period and dose [82]. 
Table 1. The in Vitro Toxicity Effects of 0-D and 1-D Carbon Nanomaterials.

\begin{tabular}{|c|c|c|c|}
\hline $\begin{array}{l}\text { Carbon Nanomaterial; } \\
\text { Nanoparticle } \\
\text { Dimension }\end{array}$ & $\begin{array}{l}\text { Cell Line; } \\
\text { Concentrations; } \\
\text { Exposure }\end{array}$ & Toxicity Effects & Reference \\
\hline $\begin{array}{c}\text { PEI-CQDs; PS }=6.5 \pm 2 \\
\mathrm{~nm}, \mathrm{HD}=56.54 \mathrm{~nm}\end{array}$ & $\begin{array}{l}\text { Kidney epithelial cells } \\
\text { (African green monkey); } \\
200,400,600 \text { and } \\
800 \mu \mathrm{g} / \mathrm{mL} ; 48 \mathrm{~h}\end{array}$ & $\begin{array}{l}\text { PEI-CQDs exhibited toxic effects } \\
\text { above concentration } 600 \mu \mathrm{g} / \mathrm{mL} \text {. }\end{array}$ & [46] \\
\hline $\begin{array}{l}\text { CQDs; PS = } 7 \mathrm{~nm}, \\
\mathrm{HD}=60.3 \pm 7 \mathrm{~nm}\end{array}$ & $\begin{array}{l}\text { Human bronchial } \\
\text { epithelial cells (16HBE); } \\
1,10,50,100 \text { and } \\
200 \mu \mathrm{g} / \mathrm{mL} ; 24 \mathrm{~h}\end{array}$ & $\begin{array}{l}\text { CQDs reduced cell viability } \\
\text { inducing oxidative stress. }\end{array}$ & [47] \\
\hline $\begin{array}{l}\text { OH-GQDs; PS = 5.6 } \pm 1.1 \\
\mathrm{~nm}, \mathrm{HD}=10.3 \pm 1.9 \mathrm{~nm}\end{array}$ & $\begin{array}{l}\text { Human lung carcinoma } \\
\text { cell lines (H1299 and } \\
\text { A549); } 12.5,25,50 \text { and } \\
100 \mu \mathrm{g} / \mathrm{mL} ; 24 \text { and } 48 \mathrm{~h}\end{array}$ & $\begin{array}{l}\text { The hydroxylated GQDs } \\
\text { induced cell senescence and } \\
\text { inhibited } \mathrm{Rb} \text { phosphorylation in } \\
\text { both types of cells at } \\
\text { concentration } 50 \mu \mathrm{g} / \mathrm{mL} \text {. }\end{array}$ & {$[50]$} \\
\hline GQDs; PS = 20 nm & $\begin{array}{l}\text { Human breast cancer } \\
\text { cells (MCF-7) and human } \\
\text { gastric cancer cells } \\
\text { (MGC-803); 20, 100, } 200 \\
\text { and } 400 \mu \mathrm{g} / \mathrm{mL} ; 24 \mathrm{~h}\end{array}$ & $\begin{array}{l}\text { GQDs were found less cytotoxic } \\
\text { on both type of cells though the } \\
\text { nanoparticles permeated into } \\
\text { cytoplasm and nucleus. }\end{array}$ & {$[51]$} \\
\hline NDs; PS $=4-5 \mathrm{~nm}$ & $\begin{array}{l}\text { Mouse embryonic stem } \\
\text { cells; } 5 \text { or } 100 \mu \mathrm{g} / \mathrm{mL} ; \\
24 \mathrm{~h}\end{array}$ & $\begin{array}{l}\text { NDs exhibited genotoxicity, } \\
\text { expressing an increased level of } \\
\text { DNA repair proteins. }\end{array}$ & {$[52]$} \\
\hline NDs; HD = 41-103 nm & $\begin{array}{l}\text { Human keratinocyte } \\
\text { (HaCaT) and human } \\
\text { alveolar basal epithelial } \\
\text { cells (A549); } 0.01,0.1 \text { and } \\
1.0 \mathrm{mg} / \mathrm{mL} ; 6 \text { and } 24 \mathrm{~h}\end{array}$ & $\begin{array}{l}\text { NDs were not involved in } \\
\text { decreasing cell viability and } \\
\text { generating intracellular ROS. } \\
\text { However, the nanoparticles } \\
\text { inhibited colony formation in } \\
\text { cells even at concentration } \\
1.0 \mathrm{mg} / \mathrm{mL} \text {. }\end{array}$ & [53] \\
\hline NDs; PS = 6-500 nm & $\begin{array}{c}\text { Mouse macrophages } \\
\text { (RAW 264.7); 0, 10, 50, } \\
100 \text { and } 200 \mu \mathrm{g} / \mathrm{mL} ; 24 \mathrm{~h}\end{array}$ & $\begin{array}{l}\text { The results revealed that NDs } \\
\text { reduced cell proliferation and } \\
\text { metabolic activity in a dose } \\
\text { dependent manner. }\end{array}$ & {$[54]$} \\
\hline $\begin{array}{c}\text { CBNPs; } \\
\mathrm{PS}=260 \pm 13.7 \mathrm{~nm}\end{array}$ & $\begin{array}{c}\text { A549 cells; } 0.39 \text { and } \\
0.78 \mu \mathrm{g} / \mathrm{mL} ; 24 \text { and } 48 \mathrm{~h}\end{array}$ & $\begin{array}{l}\text { Size dependent cytotoxicity was } \\
\text { observed in CBNPs treated cells. } \\
\text { Ultrafine CBNPs affected more } \\
\text { oxidative stress in cells than } \\
\text { fine CBNPs. }\end{array}$ & [59] \\
\hline CBNPs; PS = $14 \mathrm{~nm}$ & $\begin{array}{l}\text { FE1-Muta mouse lung } \\
\text { epithelial cell line; } \\
75 \mu \mathrm{g} / \mathrm{mL} ; 8 \times 72 \mathrm{~h}\end{array}$ & $\begin{array}{l}\text { CBNPs caused genetic mutation } \\
\text { increasing the quantity of } \\
\text { oxidized purines. }\end{array}$ & {$[61]$} \\
\hline $\begin{array}{l}\text { CBNPs; PS = } 14 \mathrm{~nm} \\
\mathrm{SSA}=300 \mathrm{~m}^{2} / \mathrm{g}\end{array}$ & $\begin{array}{l}\text { RAW } 264.7 \text { cells; } 0.25,10, \\
25,50 \text { and } 100 \mu \mathrm{g} / \mathrm{mL} ; 24, \\
48 \text { and } 72 \mathrm{~h}\end{array}$ & $\begin{array}{l}\text { Cytotoxic and genotoxic effects } \\
\text { were observed, along with the } \\
\text { formation of acentric } \\
\text { chromosome fragments at all } \\
\text { concentrations. }\end{array}$ & [63] \\
\hline CBNPs; PS = $14 \mathrm{~nm}$ & $\begin{array}{l}\text { A549 cells; } 100 \mu \mathrm{g} / \mathrm{mL} ; \\
0.5-24 \mathrm{~h}\end{array}$ & $\begin{array}{c}\text { CBNPs induced DNA } \\
\text { single-strand breaks at } \\
100 \mu \mathrm{g} / \mathrm{mL} \text { at } 3 \mathrm{~h} \text { of post } \\
\text { exposure. }\end{array}$ & {$[64]$} \\
\hline
\end{tabular}


Table 1. Cont

\begin{tabular}{|c|c|c|c|}
\hline $\begin{array}{l}\text { Carbon Nanomaterial; } \\
\text { Nanoparticle } \\
\text { Dimension }\end{array}$ & $\begin{array}{l}\text { Cell Line; } \\
\text { Concentrations; } \\
\text { Exposure }\end{array}$ & Toxicity Effects & Reference \\
\hline $\mathrm{C} 60 ; \mathrm{PS}=0.7 \mathrm{~nm}$ & $\begin{array}{l}\text { FE1-Muta mouse lung } \\
\text { epithelial cells; } \\
100 \mu \mathrm{g} / \mathrm{mL} ; 576 \mathrm{~h}\end{array}$ & $\begin{array}{l}\text { C60 increased the level of } \\
\text { oxidized purines significantly } \\
\text { without affecting DNA strands. }\end{array}$ & [66] \\
\hline $\mathrm{C} 60 ; \mathrm{PS}=0.7 \mathrm{~nm}$ & $\begin{array}{c}\text { A549 cells; } \\
0.02-200 \mu \mathrm{g} / \mathrm{mL} ; 48 \mathrm{~h}\end{array}$ & $\begin{array}{l}\text { C60 treated cells witnessed } \\
\text { increased micronuclei frequency } \\
\text { depending on dosage. }\end{array}$ & [67] \\
\hline $\mathrm{C} 60(\mathrm{OH}) \mathrm{n}$ & $\begin{array}{l}\text { Chinese hamster ovary } \\
\text { cells }(\mathrm{CHO} \mathrm{K} 1) \\
11-221 \mu \mathrm{M} ; 24 \mathrm{~h}\end{array}$ & $\begin{array}{l}\text { The nanoparticles treated cells } \\
\text { showed decreased micronuclei } \\
\text { frequency and chromosome } \\
\text { aberration in a dose } \\
\text { dependent manner. }\end{array}$ & [27] \\
\hline $\begin{array}{c}\text { C60(OH)n; } \\
\text { PS = 7.1 } 2.4 \mathrm{~nm}\end{array}$ & $\begin{array}{l}\text { Human umbilical } \\
\text { vascular endothelial cells; } \\
1-100 \mu \mathrm{g} / \mathrm{mL} ; 24 \mathrm{~h}\end{array}$ & $\begin{array}{c}\text { The hydroxylated C60 decreased } \\
\text { cell viability in a concentration } \\
\text { dependent manner. }\end{array}$ & [69] \\
\hline SWCNTs; n/a & $\begin{array}{c}\text { Human embryonic } \\
\text { kidney cells (HEK293T); } \\
0.78,1.56,3.12,6.25,12.5 \\
25,50,100,150 \text { and } \\
200 \mu \mathrm{g} / \mathrm{mL} ; 0-5 \text { days }\end{array}$ & $\begin{array}{l}\text { SWCNTs decreased cell } \\
\text { adhesion and inhibited cell } \\
\text { proliferation depending on dose } \\
\text { and time. }\end{array}$ & [70] \\
\hline $\begin{array}{l}\text { SWCNTs; } \\
\mathrm{L}=300-1000 \mathrm{~nm}, \\
\mathrm{~W}=1 \mathrm{~nm}\end{array}$ & $\begin{array}{l}\text { Murine } 3 \mathrm{~T} 3 \text { and human } \\
\text { 3T6 fibroblast cells; } 1,5 \\
\text { and } 10 \mu \mathrm{M} ; 1 \mathrm{~h}\end{array}$ & $\begin{array}{l}\text { The nanoparticles had the } \\
\text { potential to permeate the cell } \\
\text { and exhibited toxicity above } \\
10 \mu \mathrm{M} \text {. }\end{array}$ & [73] \\
\hline $\begin{array}{c}\text { SWCNTs; } \\
\text { PS }=0.8-2.0 \mathrm{~nm}\end{array}$ & $\begin{array}{c}\text { Normal and malignant } \\
\text { human mesothelial cells; } \\
12.5,25 \text { and } 125 \mu \mathrm{g} / \mathrm{cm}^{2} ; \\
24 \mathrm{~h}\end{array}$ & $\begin{array}{l}\text { DNA damage, cell death, and } \\
\text { ROS generation were observed } \\
\text { in nanoparticles treated cells. }\end{array}$ & [77] \\
\hline $\begin{array}{c}\text { SWCNTs; PS = 0.4-1.2 } \\
\mathrm{nm}, \mathrm{SSA}=1040 \mathrm{~m}^{2} / \mathrm{g}\end{array}$ & $\begin{array}{c}\text { Chinese hamster lung } \\
\text { V79 fibroblasts; } 0,24,48 \\
\text { and } 96 \mu \mathrm{g} / \mathrm{cm}^{2} ; 3 \text { and } \\
24 \mathrm{~h}\end{array}$ & $\begin{array}{l}\text { SWCNTs caused DNA damage } \\
\text { in cells at } 24 \mathrm{~h} \text { of post-exposure. }\end{array}$ & [78] \\
\hline $\begin{array}{l}\text { MWCNTs; PS }=67 \mathrm{~nm}, \\
\quad \mathrm{SSA}=26 \mathrm{~m}^{2} / \mathrm{g}\end{array}$ & $\begin{array}{l}\text { Mouse macrophages } \\
\text { (J774.1 and CHO-K1); } \\
10-1000 \mu \mathrm{g} / \mathrm{mL} ; 16-32 \mathrm{~h}\end{array}$ & $\begin{array}{l}\text { MWCNTs treated cells exhibited } \\
\text { larger cytotoxicity than } \\
\text { crocidolite treated cells. }\end{array}$ & [79] \\
\hline MWCNTs; PS = 100 nm & $\begin{array}{c}\text { Human epidermal } \\
\text { keratinocytes (HEK) } \\
\text { cells; } 0.1,0.2 \text { and } 0.4 \\
\mathrm{mg} / \mathrm{mL} ; 1,2,4,8,12,24 \\
\text { and } 48 \mathrm{~h}\end{array}$ & $\begin{array}{l}\text { MWCNTs penetrated the cell } \\
\text { membrane and altered the gene } \\
\text { expression level of various } \\
\text { proteins. }\end{array}$ & [80] \\
\hline MWCNTs; PS = $30 \mathrm{~nm}$ & $\begin{array}{c}\text { Human skin fibroblasts } \\
\text { (HSF42); } 0.06,0.6 \text { and } \\
6 \mu \mathrm{g} / \mathrm{mL} ; 48 \mathrm{~h}\end{array}$ & $\begin{array}{l}\text { MWCNTs caused an increase in } \\
\text { apoptosis and necrosis } \\
\text { disrupting intracellular } \\
\text { signaling pathways, cell } \\
\text { metabolism and cellular } \\
\text { transport. }\end{array}$ & [81] \\
\hline $\begin{array}{l}\text { MWCNTs; } \mathrm{L}=1-5 \mu \mathrm{m} \\
\mathrm{W}=20-40 \mathrm{~nm}\end{array}$ & $\begin{array}{c}\text { Human blood } \mathrm{T} \\
\text { lymphocytes; } 10 \mathrm{ng} / \mathrm{cell} ; \\
0,24,48,72,96 \text { and } 120 \mathrm{~h}\end{array}$ & $\begin{array}{l}\text { The oxidized form of MWCNTs } \\
\text { exhibited more cytotoxicity than } \\
\text { pristine MWCNTs. Both types of } \\
\text { nanoparticles induced apoptosis } \\
\text { in cells in a time and dose } \\
\text { dependent manner. }\end{array}$ & [82] \\
\hline
\end{tabular}

Abbreviations: PS, particle size; HD, hydrodynamic diameter; SSA, specific surface area; L, length; W, width; n/a, not available. 


\section{In Vivo Toxicity of Zero-and One-Dimensional Carbon Nanomaterials}

In some studies, the researchers performed in vivo animal studies of carbon nanomaterials after the careful evaluation of their in vitro toxicity measurements, and some of studies are listed in Table 2.

Table 2. The in Vivo Toxicity Effects of 0-D and 1-D Carbon Nanomaterials.

\begin{tabular}{|c|c|c|c|}
\hline $\begin{array}{l}\text { Carbon Nanomaterial; } \\
\text { Nanoparticle } \\
\text { Dimension }\end{array}$ & $\begin{array}{c}\text { Animal Model; } \\
\text { Concentrations; Exposure }\end{array}$ & Toxicity Effects & Reference \\
\hline $\begin{array}{c}\text { CQDs; PS } \leq 10 \mathrm{~nm}, \mathrm{HD}= \\
40 \mathrm{~nm}, \mathrm{IS}=0.32 \mathrm{~nm}\end{array}$ & $\begin{array}{c}\text { Zebrafish; } 0,10,30,50,70, \\
100 \text { and } 200 \mathrm{mg} / \mathrm{L} ; 0,24,48, \\
72, \text { and } 96 \mathrm{~h} \\
\text { Zooplankton; } 0,10,30,50,70, \\
100 \text { and } 200 \mathrm{mg} / \mathrm{L} ; 48 \mathrm{~h} \\
\text { Phytoplankton; } 0,5,10,50, \\
100,200 \text { and } 500 \mathrm{mg} / \mathrm{L} ; 0,24, \\
48,72 \text {, and } 96 \mathrm{~h}\end{array}$ & $\begin{array}{l}\text { CQDs, at higher dose of } 200 \mathrm{mg} / \mathrm{L} \text {, } \\
\text { did not affect swimming and } \\
\text { feeding behaviors. } \\
\text { CQDs exhibited moderate toxicity } \\
\text { to zooplankton, inducing mortality } \\
\text { and immobility with EC } 50 \text { value } \\
97.5 \mathrm{mg} / \mathrm{L} \text {. } \\
\text { CQDs induced oxidative stress and } \\
\text { water acidification, inhibited } \\
\text { photosynthesis and depleted } \\
\text { nutrition absorption in a dose and } \\
\text { time dependent manner. It retarded } \\
\text { the growth of phytoplankton with } \\
\text { EC50 value } 74.8 \text { mg/L at } 96 \text { h of the } \\
\text { study. }\end{array}$ & [83] \\
\hline CQDs; PS = 1-5 nm & $\begin{array}{l}\text { Male and female ICR mice; } \\
250,320,400 \text { and } 500 \mathrm{mg} / \mathrm{kg} \text {, } \\
\text { single dose, intravenous } \\
\text { injections; } 14 \text { day } \\
\text { sMale ICR mice; } 100 \mathrm{mg} / \mathrm{kg}, \\
\text { repeated dose, intravenous } \\
\text { injections; } 1,7,30 \text { and } 90 \\
\text { days, once/day }\end{array}$ & $\begin{array}{l}\text { Male mice (LD50 } 391.62 \mathrm{mg} / \mathrm{kg} \text { ) } \\
\text { were found to be more sensitive to } \\
\text { the higher doses of the } \\
\text { nanoparticles than female mice } \\
\text { (LD50 } 357.77 \mathrm{mg} / \mathrm{kg} \text { ). } \\
\text { An acute inflammatory response } \\
\text { was observed after seven doses, } \\
\text { however the data on the body } \\
\text { weight, organ coefficients, blood } \\
\text { biochemistry, and organ } \\
\text { histopathology suggested that the } \\
\text { nanoparticles had low toxicity } \\
\text { during the entire experimental } \\
\text { period. }\end{array}$ & [84] \\
\hline CQDs; PS = 2-6 nm & $\begin{array}{c}\text { Male and female } \\
\text { embryos/larvae of rare } \\
\text { minnows; } 0,1,5,10,20,40, \\
\text { and } 80 \mathrm{mg} / \mathrm{L} ; 12-96 \mathrm{hpf}\end{array}$ & $\begin{array}{l}\text { In lower dose treated groups }(1,5, \\
\text { 10, and } 20 \mathrm{mg} / \mathrm{L}) \text {, no significant } \\
\text { developmental defects were } \\
\text { observed at the stage of } 12 \mathrm{hpf}, \\
\text { whereas higher dose treated groups } \\
\text { (40 mg/L and } 80 \mathrm{mg} / \mathrm{L}) \text { caused } \\
\text { embryos yolk agglutination in a } \\
\text { concentration-dependent manner. } \\
\text { The noticeable time-dependent } \\
\text { deleterious effects were decreased } \\
\text { spontaneous movements, higher } \\
\text { heart rate, and increased hatching } \\
\text { rate. Most of the unhatched } \\
\text { embryos died when the exposure } \\
\text { time reached } 96 \text { hpf. }\end{array}$ & [9] \\
\hline CQDs; PS = $8 \pm 2 \mathrm{~nm}$ & $\begin{array}{c}\text { Male ICR mice; 0, 6, } 12 \text { and } \\
24 \mathrm{mg} / \mathrm{kg} \text {, intraperitoneal } \\
\text { injection; } 30 \text { days }\end{array}$ & $\begin{array}{l}\text { The histopathological examination } \\
\text { showed that no obvious toxic effects } \\
\text { were triggered by CQDs on mice. } \\
\text { However, NMR metabolomic } \\
\text { profiles revealed that CQDs could } \\
\text { affect cell membrane, immune } \\
\text { system, and normal liver clearance. }\end{array}$ & [8] \\
\hline
\end{tabular}


Table 2. Cont

\begin{tabular}{|c|c|c|c|}
\hline $\begin{array}{l}\text { Carbon Nanomaterial; } \\
\text { Nanoparticle } \\
\text { Dimension }\end{array}$ & $\begin{array}{c}\text { Animal Model; } \\
\text { Concentrations; Exposure }\end{array}$ & Toxicity Effects & Reference \\
\hline $\begin{array}{l}\text { GQDs; PS = 2.3-6.4 nm, } \\
\text { IS }=0.36 \mathrm{~nm} \text {, height }= \\
0.6-3.5 \mathrm{~nm}, 1-3 \text { layers }\end{array}$ & $\begin{array}{l}\text { AB strains of wild-type } \\
\text { zebrafish embryo/larva; } 0, \\
12.5,25,50,100 \text { and } 200 \\
\mu \mathrm{g} / \mathrm{mL} ; 4-120 \mathrm{hpf}\end{array}$ & $\begin{array}{l}\text { The heart rate of treated animals } \\
\text { was found to be decreased with a } \\
\text { dose-dependent effect. The } \\
\text { exposure of GQDs suggested that } \\
\text { they might have little effect during } \\
\text { the heart development stage of } \\
\text { zebrafish embryos and larvae. }\end{array}$ & [85] \\
\hline $\begin{array}{c}\text { GQDs, } P S=3.315 \pm 1.74 \\
n m\end{array}$ & $\begin{array}{l}\text { AB strains of wild-type } \\
\text { zebrafish embryo/larva; } 0 \text {, } \\
\text { 12.5, 25, 50, 100, and } 200 \\
\mu \mathrm{g} / \mathrm{mL} ; 4-96 \mathrm{hpf}\end{array}$ & $\begin{array}{l}\text { At low concentrations of GQDs, no } \\
\text { significant toxicity was observed. } \\
\text { When the concentration was above } \\
50 \mu \mathrm{g} / \mathrm{mL}, \mathrm{GQDs} \text { disturbed the } \\
\text { embryonic development. The } \\
\text { hatching rate and heart rate were } \\
\text { decrease, accompanied with an } \\
\text { increase in mortality. At high } \\
\text { concentration of GQDs ( } 200 \mu \mathrm{g} / \mathrm{mL}) \text {, } \\
\text { various embryonic malformations } \\
\text { including pericardial edema, } \\
\text { vitelline cyst, bent tail, and bent } \\
\text { spine occurred. }\end{array}$ & [86] \\
\hline $\begin{array}{c}\text { PEG-GQDs; PS = 3-5 nm, } \\
\text { height }=0.5-1 \mathrm{~nm}, 1-2 \\
\text { layers }\end{array}$ & $\begin{array}{c}\text { Female BALB/c mice; } 20 \\
\mathrm{mg} / \mathrm{kg} \text {, intraperitoneal } \\
\text { injection, multiple doses; } 2 \\
\text { weeks }\end{array}$ & $\begin{array}{l}\text { PEG-GQDs exhibited no-toxicity } \\
\text { effects because of nanoparticle } \\
\text { encapsulation. }\end{array}$ & [87] \\
\hline $\begin{array}{c}\text { COOH-GQDs; PS }=3-6 \\
\text { nm }\end{array}$ & $\begin{array}{l}\text { SD rats; } 5 \text { and } 10 \mathrm{mg} / \mathrm{kg} \text {, } \\
\text { intravenous injection; } 7 \\
\text { doses in } 22 \text { days with an } \\
\text { interval of } 2 \text { days }\end{array}$ & $\begin{array}{l}\text { The studies revealed that the GQDs } \\
\text { were distributed in liver, spleen, } \\
\text { lung, kidney, and tumor sites after } \\
\text { injection, however there was no } \\
\text { obvious organ damage at } 21 \text { days of } \\
\text { post-administration. The serum } \\
\text { biochemistry and complete blood } \\
\text { count studies revealed that the } \\
\text { GQDs did not cause any significant } \\
\text { toxicity to the treated animals. }\end{array}$ & [88] \\
\hline $\mathrm{NDs} ; \mathrm{HD}=\sim 120 \mathrm{~nm}$ & $\begin{array}{l}\text { Wild type young } \\
\text { Caenorhabditis elegans; } 0.5 \\
\text { mg/mL, microinjection }\end{array}$ & $\begin{array}{l}\text { The NDs were found in the distal } \\
\text { gonad and oocytes at } 30 \text { min after } \\
\text { injection. No detectable toxicity } \\
\text { effects were found in brood size and } \\
\text { longevity of the treated animal } \\
\text { groups. }\end{array}$ & [89] \\
\hline $\begin{array}{l}\text { NDs; PS }=4 \text { and } 50 \mathrm{~nm}, \\
\text { IS }=0.202 \mathrm{~nm}\end{array}$ & $\begin{array}{l}\text { Male ICR mice; } 1.0 \mathrm{mg} / \mathrm{kg}, \\
\text { intratracheal instillation; } 1,7, \\
14 \text { and } 28 \text { days of } \\
\text { post-exposure }\end{array}$ & $\begin{array}{l}\text { At } 1 \text { day of post-exposure, both } \\
\text { kinds of nanoparticles produced a } \\
\text { temporary increase in lung index } \\
\text { but there was no trace of lipid } \\
\text { peroxidation in lung tissue. During } \\
\text { the whole exposure period, the } \\
\text { burden of nanoparticle in } \\
\text { macrophages was observed and the } \\
\text { number of nanoparticles decreased } \\
\text { by time in alveolar. }\end{array}$ & [90] \\
\hline
\end{tabular}


Table 2. Cont

\begin{tabular}{|c|c|c|c|}
\hline $\begin{array}{l}\text { Carbon Nanomaterial; } \\
\text { Nanoparticle } \\
\text { Dimension }\end{array}$ & $\begin{array}{c}\text { Animal Model; } \\
\text { Concentrations; Exposure }\end{array}$ & Toxicity Effects & Reference \\
\hline $\begin{array}{c}\text { NDs; PS }=2-10 \mathrm{~nm} \text { and } \\
40-100 \mathrm{~nm}\end{array}$ & $\begin{array}{c}\text { Male Kun Ming mice; } \\
\text { intratracheal instillation; } 0.8, \\
4 \text { and } 20 \mathrm{mg} / \mathrm{kg} ; 3 \text { days }\end{array}$ & $\begin{array}{c}\text { A dose-dependent toxicity effect } \\
\text { was observed in the lung tissue of } \\
\text { mice at } 3 \text { days of post-exposure of } \\
\text { both kinds of nanoparticles and the } \\
\text { higher concentration treated mice }(4 \\
\text { and } 20 \mathrm{mg} / \mathrm{kg} \text { ) exhibited significant } \\
\text { toxicity. }\end{array}$ & [13] \\
\hline NDs-BSA; PS = 100 nm & $\begin{array}{c}\text { Zebrafish (AB strain) } \\
\text { embryos/larvae; 1, 2, } 5 \\
\text { mg/mL; 4-96 hpf }\end{array}$ & $\begin{array}{l}\text { The different stages of zebrafish } \\
\text { embryos exhibited similar } \\
\text { development when compared to the } \\
\text { control groups at a lower } \\
\text { concentration of NDs ( } 1 \mathrm{mg} / \mathrm{mL}) \text {. } \\
\text { However, a higher concentration of } \\
\text { NDs affected the zebrafish embryos } \\
\text { at the Pharyngula stage. The } \\
\text { medium concentrated NDs ( } 2 \text { and } 5 \\
\text { mg/mL) caused fin curving of } \\
\text { zebrafish larvae at the hatching } \\
\text { stage. }\end{array}$ & [14] \\
\hline CBNPs; PS = $14 \mathrm{~nm}$ & $\begin{array}{l}\text { Female C57BL/6J mice, } 10 \\
\text { mg/mouse, intratracheal } \\
\text { instillation; } 21 \text { days }\end{array}$ & $\begin{array}{l}\text { CBNPs did not exert any significant } \\
\text { adverse clinical effects. However, } \\
\text { the histopathological studies } \\
\text { revealed that they decreased lung } \\
\text { compliance inducing inflammation } \\
\text { when administered along with } \\
\text { bleomycin. They augmented the } \\
\text { levels of CCL2, TGF-b1, KC, IL-6, } \\
\text { and nitrotyrosine in mice on } \\
\text { different days of exposure. }\end{array}$ & [91] \\
\hline $\begin{array}{c}\text { CBNPs; PS }=14 \text { and } 56 \\
\mathrm{~nm}\end{array}$ & $\begin{array}{l}\text { Male ICR mice; } 50 \mu \mathrm{g} / \mathrm{body}, \\
\text { intratracheal instillation; } 1,7 \\
\text { or } 14 \text { days }\end{array}$ & $\begin{array}{l}\text { CBNPs of } 14 \mathrm{~nm} \text { aggravated porcine } \\
\text { pancreatic elastase mediated } \\
\text { pulmonary exposure on } \\
\text { emphysematous lung injury at an } \\
\text { early stage (day 1) and expressed } \\
\text { more interleukin-b and } \\
\text { keratinocyte-derived } \\
\text { chemoattractant. CBNPs of } 56 \mathrm{~nm} \\
\text { caused inflammation but did not } \\
\text { induce porcine pancreatic elastase } \\
\text { triggered pathophysiology in the } \\
\text { lung. }\end{array}$ & [92] \\
\hline $\begin{array}{l}\text { CBNPs; PS }=14 \mathrm{~nm}, \text { SSA } \\
=295-338 \mathrm{~m}^{2} / \mathrm{g}\end{array}$ & $\begin{array}{c}\text { Time mated C57BL/6BomTac } \\
\text { mice, } 42 \mathrm{mg} / \mathrm{m}^{3}, \text { whole-body } \\
\text { inhalation; } 1 \mathrm{~h} / \text { day on } \\
\text { gestation days (GD) } 8-18 \\
\text { days } \\
11,54 \text { and } 268 \mu \mathrm{g} / \text { animal, } \\
\text { intratracheal instillation; } 1 \\
\text { h/day, GD } 7,10,15 \text { and } 18 \\
\text { days }\end{array}$ & $\begin{array}{l}\text { The whole-body inhalation induced } \\
\text { significant DNA strand breaks in } \\
\text { the liver of mothers and their } \\
\text { offspring, whereas the intratracheal } \\
\text { instillation did not have that effect. } \\
\text { However, gestation and lactation } \\
\text { were not affected in both ways of } \\
\text { administrations. The pulmonary } \\
\text { inflammation in time mated mice } \\
\text { was similar in both administrations } \\
\text { for the medium dose of } \\
\text { nanoparticles. }\end{array}$ & [17] \\
\hline
\end{tabular}


Table 2. Cont

\begin{tabular}{|c|c|c|c|}
\hline $\begin{array}{l}\text { Carbon Nanomaterial; } \\
\text { Nanoparticle } \\
\text { Dimension }\end{array}$ & $\begin{array}{c}\text { Animal Model; } \\
\text { Concentrations; Exposure }\end{array}$ & Toxicity Effects & Reference \\
\hline $\begin{array}{l}\text { CBNPs; PS = } 14 \mathrm{~nm}, \mathrm{SSA} \\
\quad=295-338 \mathrm{~m}^{2} / \mathrm{g}\end{array}$ & $\begin{array}{c}\text { Female C57BL/6 mice; } 162 \\
\mu \mathrm{g} / \text { mouse, intratracheal } \\
\text { instillation; } 3 \mathrm{~h}, 1,2,3,4,5, \\
14 \text { and } 42 \text { days }\end{array}$ & $\begin{array}{l}\text { In the initial days of post-exposure, } \\
\text { the worsening of pulmonary } \\
\text { homeostasis occurred by the } \\
\text { induction of oxidative stress, DNA } \\
\text { strand breaks, cell cycle arrest, and } \\
\text { cell death. Multiple chronic } \\
\text { pulmonary inflammatory processes } \\
\text { were the possible effects at the later } \\
\text { points of post-exposure days. }\end{array}$ & [18] \\
\hline $\begin{array}{c}\text { CBNPs; GMD }=53 \pm 1.57 \\
\mathrm{~nm}\end{array}$ & $\begin{array}{c}\text { Male C57BL/6 mice; } 12.5 \\
\mu \mathrm{g} / \mathrm{m}^{3} \text {, nasal inhalation; } 4 \\
\text { h/day, } 7 \text { days }\end{array}$ & $\begin{array}{c}\text { The histopathology analyses } \\
\text { revealed that the inhalation of } \\
\text { nanoparticles exacerbated lung } \\
\text { inflammation expressing a } \\
\text { significant level of interleukin-6, } \\
\text { interferon- } \gamma \text {, and fibronectin in lung } \\
\text { tissues. }\end{array}$ & [93] \\
\hline $\begin{array}{c}\text { PAH-CBNPs; PS }=14.2 \pm \\
0.1 \mathrm{~nm}, \mathrm{SSA}=115 \pm 3 \\
\mathrm{~m}^{2} / \mathrm{g}\end{array}$ & $\begin{array}{l}\text { Male Wistar rats (strain Crl: } \\
\text { WI (Han)); } 6 \mathrm{mg} / \mathrm{m}^{3} \text {, nasal } \\
\text { inhalation; } 6 \mathrm{~h} / \text { day, } 2 \text { weeks }\end{array}$ & $\begin{array}{l}\text { A significant increase in } \\
\text { polymorphonuclear granulocyte } \\
\text { numbers was observed for the } \\
\text { animals treated with CBNPs and } \\
\text { PAH-CBNPs when compared to } \\
\text { clean air control on day } 1 \\
\text { post-exposure. PAH-CBNPs } \\
\text { induced bronchioalveolar } \\
\text { hyperplasia, whereas CBNPs caused } \\
\text { very slight histological alterations } \\
\text { on day } 14 \text { post-exposure. When } \\
\text { compared to control, only } \\
\text { PAH-CBNPs exhibited significant } \\
\text { IL-6 mRNA expression and } \\
\text { keratinocyte chemoattractant. }\end{array}$ & [94] \\
\hline \multirow[t]{2}{*}{$\begin{array}{c}\mathrm{C} 60 ; \mathrm{PS}=33 \mathrm{~nm}, \mathrm{SSA}= \\
104.6 \mathrm{~m}^{2} / \mathrm{g}\end{array}$} & $\begin{array}{c}\text { Male Wistar rats; } 0.33,0.66 \\
\text { and } 3.3 \mathrm{mg} / \mathrm{kg} \text {, intratracheal } \\
\text { instillation; } 3 \text { days, } 1 \text { week, } 1 \text {, } \\
\quad 3 \text { and } 6 \text { months }\end{array}$ & $\begin{array}{l}\text { No significant increase was } \\
\text { observed in total cell count and in } \\
\text { the expression of the } \\
\text { cytokine-induced neutrophil } \\
\text { chemoattractants CINC-1, }-2 \alpha \beta \text { and } \\
-3 \text { at a low dose of fullerene treated } \\
\text { groups. The higher dose of fullerene } \\
\text { treated rat group showed a } \\
\text { significant increase in gene } \\
\text { expression and total cell counts. }\end{array}$ & [95] \\
\hline & $\begin{array}{l}\text { Male Wistar rats; } 0.12 \pm 0.03 \\
\mathrm{mg} / \mathrm{m}^{3} \text {, whole-body } \\
\text { inhalation; } 4 \text { weeks, } 6 \mathrm{~h} / \text { day, } \\
5 \text { days/week }\end{array}$ & $\begin{array}{l}\text { There were no significant changes in } \\
\text { total cell count in BALF and gene } \\
\text { expression of CINC-1, }-2 \alpha \beta \text { and }-3 \\
\text { in lung tissue. }\end{array}$ & \\
\hline $\begin{array}{c}\mathrm{C} 60 ; \mathrm{GMD}=96 \mathrm{~nm}, \mathrm{SSA} \\
=0.92 \mathrm{~m}^{2} / \mathrm{g}\end{array}$ & $\begin{array}{c}\text { Male Wistar rats; } 0.12 \mathrm{mg} / \mathrm{m}^{3} \\
\text { whole-body inhalation; } 4 \\
\text { weeks } 6 \mathrm{~h} / \text { day, } 5 \text { days/week }\end{array}$ & $\begin{array}{l}\text { Gene expression profiles revealed } \\
\text { that the major histocompatibility } \\
\text { complex (MHC) mediated immunity } \\
\text { and metalloendopeptidase activity } \\
\text { were upregulated at } 3 \text { days and } 1 \\
\text { month of post-exposure. Some } \\
\text { upregulated genes were involved in } \\
\text { oxidative stress, inflammation, and } \\
\text { apoptosis. The nanoparticles were } \\
\text { found in alveolar epithelial cells and } \\
\text { engulfed by macrophages. }\end{array}$ & [96] \\
\hline
\end{tabular}


Table 2. Cont

\begin{tabular}{|c|c|c|c|}
\hline $\begin{array}{l}\text { Carbon Nanomaterial; } \\
\text { Nanoparticle } \\
\text { Dimension }\end{array}$ & $\begin{array}{c}\text { Animal Model; } \\
\text { Concentrations; Exposure }\end{array}$ & Toxicity Effects & Reference \\
\hline $\begin{array}{c}\mathrm{C} 60 ; \mathrm{HD}=234.1 \pm 48.9 \\
\mathrm{~nm} \text { and } 856.5 \pm 119.2 \mathrm{~nm}\end{array}$ & $\begin{array}{l}\text { gpt delta transgenic mice; } 0.2 \\
\text { mg/animal, single dose, } \\
\text { intratracheal instillation; } 3 \\
\text { hMultiple doses (4 times) }\end{array}$ & $\begin{array}{l}\text { Mutant frequencies were } \\
\text { significantly increased ( } 2-3 \text { fold) in } \\
\text { the lungs of the nanoparticle treated } \\
\text { group when compared to } \\
\text { control.There was a slight number } \\
\text { of A:T to T:A transversion in C60 } \\
\text { treated animals, while no genetic } \\
\text { transversion was observed in } \\
\text { control groups. }\end{array}$ & [67] \\
\hline $\mathrm{C} 60 ; \mathrm{PS}=46.7 \pm 18.6 \mathrm{~nm}$ & $\begin{array}{c}\text { ICR male mice; } 0.5,1,2 \\
\mathrm{mg} / \mathrm{kg} \text {, intratracheal } \\
\text { instillation; } 1,7,14 \text { and } 28 \\
\text { days }\end{array}$ & $\begin{array}{l}\text { Increase in pro-inflammatory } \\
\text { cytokines including TNF- } \alpha \text {, IL-1 } \\
\text { and IL- } 6 \text { and increase in T-cell } \\
\text { distribution were observed in C60 } \\
\text { treated mice. The gene expression of } \\
\text { MHC class } 2 \text { was greater than that } \\
\text { of MHC class } 1 \text { (H2-T23). }\end{array}$ & [97] \\
\hline $\mathrm{C} 60 ; \mathrm{HD}=407-5117 \mathrm{~nm}$ & $\begin{array}{c}\text { Female Fisher } 344 \text { rats; } \\
\text { single oral intragastric } \\
\text { administration; } 0.064 \text { and } 64 \\
\mathrm{mg} / \mathrm{kg} ; 24 \mathrm{~h}\end{array}$ & $\begin{array}{l}\text { Only high dose of fullerene } \\
\text { generated oxidative damage by } \\
\text { expressing a high level of mRNA } \\
\text { 8-oxoguanine DNA glycosylase } \\
\text { (8-oxodG) in the lung. }\end{array}$ & [98] \\
\hline C60; n/a & $\begin{array}{l}\text { Sprague-Dawley male and } \\
\text { female rats; } 2000 \mathrm{mg} / \mathrm{kg} \text {, oral } \\
\text { exposure, single dose; } 14 \\
\text { days }\end{array}$ & $\begin{array}{l}\text { No acute oral toxicity and no deaths } \\
\text { were reported. }\end{array}$ & [26] \\
\hline $\mathrm{C} 60(\mathrm{OH}) \mathrm{n}$ & $\begin{array}{l}\text { BALB/c female mice; } 0.02, \\
0.2,2.0,20 \text { and } 200 \\
\mu \mathrm{g} / \text { animal, intratracheal } \\
\text { instillation; } 24 \mathrm{~h}\end{array}$ & $\begin{array}{l}\text { The BAL data indicated that only } \\
200 \mu \mathrm{g} \text { treated mice showed } \\
\text { increased neutrophil influx in the } \\
\text { lungs causing inflammation, } \\
\text { whereas other low concentration } \\
\text { treated groups did not present any } \\
\text { significant changes. }\end{array}$ & [99] \\
\hline $\begin{array}{c}\text { SWCNTs; } \mathrm{L} \leq 1 \mu \mathrm{m}, \mathrm{W}= \\
0.9-1.7 \mathrm{~nm}\end{array}$ & $\begin{array}{l}\text { Female Fisher } 344 \text { rats; } 0.064 \\
\text { and } 64 \mathrm{mg} / \mathrm{Kg} \text {, single dose, } \\
\text { oral intragastric } \\
\text { administration; } 24 \mathrm{~h}\end{array}$ & $\begin{array}{l}\text { SWCNTs were reported to cause } \\
\text { oxidatively damaged DNA in lung } \\
\text { and liver by increasing the level of } \\
\text { 8-oxodG. }\end{array}$ & [98] \\
\hline SWCNTs; n/a & $\begin{array}{l}\text { Male Sprague-Dawley rats; } \\
0.4,2 \text { and } 4 \mathrm{mg} / \mathrm{kg} \text {, } \\
\text { intrapulmonary instillation; } \\
1,7,30 \text { and } 90 \text { days }\end{array}$ & $\begin{array}{l}\text { Increase in lung granulomatous and } \\
\text { inflammatory responses along with } \\
\text { fibrosis and collagen deposition was } \\
\text { observed in a time and } \\
\text { dose-dependent manner for } \\
\text { SWCNTs treated groups. }\end{array}$ & [41] \\
\hline $\begin{array}{l}\text { SWCNTs; } \mathrm{L}=10 \mathrm{~nm} \text { to } \\
\text { several } \mu \mathrm{m}, \mathrm{W}=1-2 \mathrm{~nm}\end{array}$ & $\begin{array}{c}\text { Male ICR mice; } 0.5 \mathrm{mg} / \mathrm{kg} \text {, } \\
\text { intratracheal instillation, } \\
\text { single dose; } 3 \text { and } 14 \text { days }\end{array}$ & $\begin{array}{l}\text { The histological data of SWCNTs } \\
\text { treated groups revealed that an } \\
\text { increase in macrophage infiltration, } \\
\text { foamy-like macrophages formation } \\
\text { in the alveolar space, and no } \\
\text { significant granuloma formation } \\
\text { were observed at } 3 \text { days of } \\
\text { investigation. Meanwhile, a } \\
\text { profound multifocal granuloma was } \\
\text { found after } 14 \text { days. }\end{array}$ & {$[40]$} \\
\hline
\end{tabular}


Table 2. Cont

\begin{tabular}{|c|c|c|c|}
\hline $\begin{array}{l}\text { Carbon Nanomaterial; } \\
\text { Nanoparticle } \\
\text { Dimension }\end{array}$ & $\begin{array}{c}\text { Animal Model; } \\
\text { Concentrations; Exposure }\end{array}$ & Toxicity Effects & Reference \\
\hline SWCNTs; n/a & $\begin{array}{l}\text { Female C57BL/6 mice; } 40 \\
\mu \mathrm{g} / \text { mouse, single dose, } \\
\text { intraperitoneal injection; } 1 \\
\text { and } 7 \text { days }\end{array}$ & $\begin{array}{l}\text { Non-degraded nanotubes treated } \\
\text { mice induced inflammation and } \\
\text { tissue granulomas, while } \\
\text { biodegraded nanotubes treated mice } \\
\text { were not induced. }\end{array}$ & [100] \\
\hline $\begin{array}{c}\text { SWCNTs; } \mathrm{L} \leq 5 \mu \mathrm{m}, \mathrm{W}= \\
\sim 8 \mathrm{~nm}\end{array}$ & $\begin{array}{l}\text { SPF male and female Wistar } \\
\text { rats; } 2 \text { and } 10 \mathrm{mg} / \mathrm{kg}, \\
\text { intratracheal instillation; } 5 \\
\text { weeks }\end{array}$ & $\begin{array}{l}\text { High dose exposure of SWCNTs } \\
\text { registered increased level of } \\
\text { inflammatory markers such as IL-1, } \\
\text { IL-6 and TNF- } \alpha \text { in BALF than low } \\
\text { dose exposure in rat lungs. } \\
\text { Transgelin } 2 \text { gene expression was } \\
\text { also found to be higher in high dose } \\
\text { treated rats. }\end{array}$ & [101] \\
\hline SWCNTs; HD = $48.4 \mathrm{~nm}$ & $\begin{array}{c}\text { Male ICR mice; } 25,50 \text { and } \\
100 \mu \mathrm{g} / \mathrm{kg} \text {, intratracheal } \\
\text { instillation; after } 24 \mathrm{~h}\end{array}$ & $\begin{array}{l}\text { The administration of SWCNTs } \\
\text { increased the secretion of IL- } 6 \text { and } \\
\text { MCP-1, and the number of total } \\
\text { cells including neutrophils, } \\
\text { lymphocytes, and eosinophils in the } \\
\text { lungs of higher dose-treated mice. }\end{array}$ & [39] \\
\hline $\begin{array}{l}\text { SWCNTs; } \mathrm{L}=\leq 1 \mu \mathrm{m}, \mathrm{W} \\
\quad=0.8-1.7 \mathrm{~nm}\end{array}$ & $\begin{array}{l}\text { Female C57BL/ } 6 \mathrm{~J} \text { mice; } 0.9, \\
2.8,8.4 \mathrm{mg} / \mathrm{kg} \text {, intratracheal } \\
\text { instillation, single dose; } 1,3 \\
\text { and } 28 \text { days }\end{array}$ & $\begin{array}{l}\text { A dose-dependent increase in Saa3 } \\
\text { mRNA expression was observed in } \\
\text { the lung. }\end{array}$ & [102] \\
\hline $\begin{array}{l}\text { SWCNTs; PS }=1-2 \mathrm{~nm}, \\
\quad \mathrm{SSA}=1040 \mathrm{~m}^{2} / \mathrm{g}\end{array}$ & $\begin{array}{l}\text { Female C57BL/6J mice; } 40 \\
\mu \mathrm{g} / \text { mouse, pharyngeal } \\
\text { aspiration, single dose; } 1,7 \\
\text { and } 28 \text { days }\end{array}$ & $\begin{array}{l}\text { The SWCNTs treated vitamin } \\
\text { E-deficient mice had shown a } \\
\text { greater decrease in pulmonary } \\
\text { antioxidants when compared to } \\
\text { controls. Acute inflammation and } \\
\text { enhanced profibrotic responses } \\
\text { were also observed. }\end{array}$ & [42] \\
\hline $\begin{array}{l}\text { SWCNTs; } \mathrm{L}=\leq 1 \mu \mathrm{m}, \mathrm{W} \\
=0.8-1.2 \mathrm{~nm}, \mathrm{SSA}= \\
\quad 400-1000 \mathrm{~m}^{2} / \mathrm{g}\end{array}$ & $\begin{array}{l}\text { Male C57BL/6J mice; } 10 \\
\mu \mathrm{g} / \text { mouse, pharyngeal } \\
\text { aspiration, single dose; } 2 \\
\text { weeks }\end{array}$ & $\begin{array}{l}\text { Both Survanta (natural lung } \\
\text { surfactant) dispersed and } \\
\text { acetone/sonication dispersed } \\
\text { SWCNTs induced lung fibrosis in } \\
\text { mice by increasing collagen } \\
\text { deposition. }\end{array}$ & [43] \\
\hline $\begin{array}{c}\text { MWCNTs; PS = 15-50 } \\
\text { nm }\end{array}$ & $\begin{array}{l}\text { Male Wistar rats; } 5 \mathrm{mg} / \mathrm{m}^{3} \text {, } \\
\text { nasal inhalation; single dose; } \\
4 \mathrm{~h}, 1,7 \text {, and } 14 \text { days }\end{array}$ & $\begin{array}{l}\text { A significant increase in cell count, } \\
\text { lactate dehydrogenase, alkaline } \\
\text { phosphatase, and cytokines and a } \\
\text { decrease in cell viability and } \\
\text { alveolar macrophage count were } \\
\text { observed in MWCNTs-treated rats } \\
\text { in all the investigated days, when } \\
\text { compared to control rats. } \\
\text { Inflammation, granuloma, and } \\
\text { fibrosis were also reported in the } \\
\text { lungs of MWCNTs-treated rats on } 7 \\
\text { and } 14 \text { days of post-exposure. }\end{array}$ & {$[32]$} \\
\hline
\end{tabular}


Table 2. Cont.

\begin{tabular}{|c|c|c|c|}
\hline $\begin{array}{c}\text { Carbon Nanomaterial; } \\
\text { Nanoparticle } \\
\text { Dimension }\end{array}$ & $\begin{array}{c}\text { Animal Model; } \\
\text { Concentrations; Exposure }\end{array}$ & Toxicity Effects & Reference \\
\hline $\begin{array}{c}\text { MWCNTs; short }(\mathrm{L}=1-5 \\
\mu \mathrm{m}, \mathrm{W}=15 \pm 5 \mathrm{~nm}) \\
\text { intermediate }(\mathrm{L}=5-20 \\
\mu \mathrm{m}, \mathrm{W}=15 \pm 5 \mathrm{~nm}) \\
\text { long }(\mathrm{L}=\sim 13 \mu \mathrm{m}, \mathrm{W}= \\
40-50 \mathrm{~nm})\end{array}$ & $\begin{array}{l}\text { Female C57Bl/6 mice; } 50 \\
\text { mg/mouse, intraperitoneal } \\
\text { injection; } 1 \text { and } 7 \text { days }\end{array}$ & $\begin{array}{l}\text { Size-dependent studies revealed } \\
\text { that long sized MWCNTs (mean } 13 \\
\mu \mathrm{m}) \text { affected significant } \\
\text { inflammation and granuloma in } \\
\text { mice at } 1 \text { and } 7 \text { days of } \\
\text { post-operation while short }(1-5 \mu \mathrm{m}) \\
\text { and intermediate }(5-20 \mu \mathrm{m}) \\
\text { MWCNTs did not cause any } \\
\text { significant changes. Furthermore, } \\
\text { short MWCNTs were readily } \\
\text { involved in phagocytosis while long } \\
\text { sized MWCNTs had frustrated } \\
\text { phagocytosis. }\end{array}$ & [103] \\
\hline $\begin{array}{c}\text { MWCNTs; } L=1.1 \pm 2.7 \\
\mu \mathrm{m}, \mathrm{W}=63 \pm 1.5 \mathrm{~nm}\end{array}$ & $\begin{array}{c}\text { Male Wistar rats; } 0.66 \text { and } \\
3.3 \mathrm{mg} / \mathrm{kg} \text {, intratracheal } \\
\text { instillation; } 3,7,30,90 \text {, and } \\
180 \text { days } \\
\text { Male Wistar rats; } \\
\text { whole-body inhalation; } 6 \\
\text { h/day, } 4 \text { weeks }\end{array}$ & $\begin{array}{l}\text { Lung inflammations and CINC-1 } \\
\text { expressions were found significantly } \\
\text { in high dose treated rats and } \\
\text { temporary inflammation was } \\
\text { observed in the low dose treated } \\
\text { groups. } \\
\text { Minimal pulmonary inflammation } \\
\text { and a temporary increase in CINC-1 } \\
\text { to CINC-3 expressions were found. }\end{array}$ & [104] \\
\hline $\begin{array}{c}\text { MWCNTs; } \mathrm{L}=5.9 \pm 0.05 \\
\mu \mathrm{m}, \mathrm{W}=9.7 \pm 2.1 \mathrm{~nm} \\
\mathrm{SSA}=378 \pm 20 \mathrm{~m}^{2} / \mathrm{g}\end{array}$ & $\begin{array}{l}\text { Female Sprague-Dawley } \\
\text { rats; } 0.5 \text { and } 2 \mathrm{mg} / \mathrm{rat}, \\
\text { intratracheal instillation; 0, } \\
\quad 28 \text { and } 60 \text { days }\end{array}$ & $\begin{array}{l}\text { At } 60 \text { days, pulmonary lesions were } \\
\text { observed for MWCNTs treated rats } \\
\text { owing to collagen-rich granulomas } \\
\text { formation protruding in the } \\
\text { bronchial lumen. TNF- } \alpha \text { was } \\
\text { excessively produced in the lungs of } \\
\text { treated animals. }\end{array}$ & [105] \\
\hline MWCNTs; n/a & $\begin{array}{l}\text { Male guinea pigs; } 12.5 \\
\text { mg/pig, intratracheal } \\
\text { instillation; } 90 \text { days }\end{array}$ & $\begin{array}{l}\text { At } 90 \text { days, the MWCNTs exposure } \\
\text { caused pneumonitis with mild } \\
\text { peribronchiolar fibrosis in pigs, } \\
\text { which was not observed in the } \\
\text { controls. }\end{array}$ & [106] \\
\hline
\end{tabular}

Abbreviations: PS, particle size; IS, interlayer spacing; HD, hydrodynamic diameter; GMD, geometric mean diameter; SSA, specific surface area; L, length; W, width; n/a, not available.

The toxicity of carbon quantum dots was investigated in different species such as zebrafish, zooplankton, and phytoplankton. The primary particle size was less than $10 \mathrm{~nm}$, with interlayer spacing of $0.32 \mathrm{~nm}$. It was found that zooplankton was more sensitive to CQDs than zebrafish and phytoplankton species and suffered oxidative stress, water acidification, insufficiency of nutrients and no photosynthesis in a time and dose-dependent manner [83]. When the nanoparticles were administered intravenously to ICR male and female mice with a single dose, it was observed that male mice are more sensitive than female mice, and that the nanoparticles treated male mice suffered severe acute inflammatory responses [84]. The intraperitoneal injection of CQDs $(8 \pm 2 \mathrm{~nm})$ into male ICR mice affected cell membrane, immune system and liver clearance rate [8]. While investigating the in vivo toxicity of CQDs $(2-6 \mathrm{~nm})$ in embryos/larvae of male and female rare minnow, concentration-dependent embryos yolk agglutination, decreased spontaneous movements, and increased heart rate were observed [9]. The toxicity studies of GQDs in AB strains of wild-type zebrafish embryos/larvae revealed that the nanoparticle had the potential to decrease heart rate, causing disrupted embryonic development in a concentration dependent manner. However, the treatment of nanoparticles did not have significant toxicity at lower doses $[85,86]$. The toxicity of functional GQDs in an animal model was studied to understand the influence of functional groups attached 
on the surface of nanoparticles. The polyethylene glycol modified GQDs (PEG-GQDs) exhibited no significant toxicity when the nanoparticles were instilled intraperitoneally into female BALB/c mice [87]. Likewise, carboxylated GQDs (COOH-GQDs) triggered no obvious damage to SD rats after 21 days of intravenous post-administration [88].

The microinjection of NDs $(0.5 \mathrm{mg} / \mathrm{mL})$ to wild type young Caenorhabditis elegans had shown no detectable toxicity in brood size and longevity of animals. The hydrodynamic diameter of the nanoparticles in solution was approximately $120 \mathrm{~nm}$ [89]. When NDs of approximately $4 \mathrm{~nm}$ were intratracheally injected into male ICR mice at a concentration of $1.0 \mathrm{mg} / \mathrm{kg}$, the nanoparticles produced lung burden during the whole exposure time, but there was no event of lipid peroxidation in lung tissue [90]. A dose-dependent toxicity was observed in the lung tissue of male Kun Ming mice after the NDs were intratracheally administered at different concentrations $0.8,4.0$ and $20 \mathrm{mg} / \mathrm{kg}$ [13]. While investigating possible toxicity of bovine serum albumin functionalized nanodiamond (ND-BSA, $\sim 100 \mathrm{~nm}$ ) in $\mathrm{AB}$ strain zebrafish embryos at a concentration range of $1-5 \mathrm{mg} / \mathrm{mL}$ and $4-96 \mathrm{~h}$ post-fertilization (hpf), it was found that the control and NDs treated groups had no significant differences in embryonic development at concentration of $1 \mathrm{mg} / \mathrm{mL}$. However, a higher concentration of NDs affected the pharyngula stage of embryos and caused fin curve in larvae during the hatching stage [14].

There were many reports that demonstrated the toxicity of carbon nanomaterials in animal models, which included pulmonary inflammation, DNA breaks, oxidative stress and elevated expression of mRNAs [17,91-106]. The intratracheally administered CBNPs (67 $\mu \mathrm{g} / \mathrm{animal})$ to female pregnant mice did not trigger significant germline mutation when compared to the control [107]. When the rats were exposed to 7.1 and $52.8 \mathrm{mg} / \mathrm{m}^{3}$ of CBNPs for 13 weeks, a significant dose-dependent increase in hypoxanthine-guanine phosphoribosyltransferase (hprt) mutation frequency was observed in rat alveolar epithelial cells. The nanoparticles impaired lung clearance, causing lung burden, and changed the expression of bronchoalveolar lavage fluid (BALF) markers of inflammation and lung injury [108]. Various immunohistochemical measurements were established to quantify DNA damage markers such as poly (ADP-ribose), 8-hydroxyguanosine, and 8-oxoguanine DNA glycosylase after intratracheally instilling CBNPs into rats for 3 months. The analyses revealed that the nanoparticles had significantly increased the expression of DNA damage markers, though the genotoxicity was less pronounced [109]. Genotoxic effects, acute phase and inflammatory responses were examined while exposing C57BL/6JBomTac mice to CBNPs. Even at low exposure doses of nanoparticles $(0.67,2,6 \mu \mathrm{g})$, an increase in DNA strand breaks occurred in bronchoalveolar lavage (BAL) cells. It was reported that DNA damage was triggered by primary genotoxicity without inflammatory responses [110]. The pulmonary toxicity of carbon black nanoparticles was studied in C57BL/6 female mice administering a single dose of $0.162 \mathrm{mg}$. An increase in expression of miRNAs such as miR-135b, miR-21, and miR-146b, which are associated with pulmonary inflammation, was observed [111]. The polycyclic aromatic hydrocarbon modified CBNPs (PAH-CBNPs) were demonstrated to express the noticeable amount of keratinocyte chemoattractant and IL-6 mRNA, when compared to uncoated CBNPs and air control when male Wistar rats were subjected to nasal inhalation exposure for 2 weeks at a concentration of $6 \mathrm{mg} / \mathrm{m}^{3}$. The primary particle size and specific surface area of functionalized CBNPs was $14.2 \pm 0.1$ and $115 \pm 3 \mathrm{~m}^{2} / \mathrm{g}$, respectively [94].

The toxicity of fullerene of $96 \mathrm{~nm}$ was studied after subjecting male Wistar rats to whole-body inhalation for 4 weeks. The experiment was carried out for $6 \mathrm{~h} /$ day with the exposure of $0.12 \mathrm{mg} / \mathrm{m}^{3}$. No significant changes were reported in the gene expression of CINC-1, CINC-2 $\alpha \beta$, and CINC-3 in lung tissue [95]. In another similar study, the upregulation of genes associated with inflammation, oxidative stress and apoptosis was noted after one month of nanoparticle exposure. The geometric mean diameter of fullerene nanoparticles was $96 \mathrm{~nm}$ and specific surface area of them was $0.92 \mathrm{~m}^{2} / \mathrm{g}$ [96]. The intratracheal instillation of C60 to gpt delta transgenic mice at a single dose of $0.2 \mathrm{mg} / \mathrm{mouse}$ induced mutant frequencies with 2-3-fold increase in comparison to the control. When administered at multiple doses (4 times), the nanoparticles brought about transversion of A:T to T:A in treated animals [67]. The 
intratracheally instilled C60 $(46.7 \pm 18.6 \mathrm{~nm})$ increased the expression of pro-inflammatory cytokines including tumor necrosis factor- $\alpha$ (TNF- $\alpha$ ), interleukins (IL-1 and IL-6) and T-cell distribution in ICR male mice [97]. It was demonstrated that single oral intragastric administration of fullerene to female Fisher 344 rats generated oxidative damage along with the expression of mRNA 8-oxoguanine DNA glycosylase (8-oxodG) in the lung at high dose [98]. No acute oral toxicity was reported for the C60 treated Sprague-Dawley male and female rats for 2 weeks [26]. The intratracheally administered fullerenol $\left(\mathrm{C} 60(\mathrm{OH})_{n}\right)$ showed increased neutrophil influx in the lungs causing inflammation in BALB/c female mice after $24 \mathrm{~h}$ of post-administration of $200 \mu \mathrm{g} /$ mouse [99].

The DNA damage was examined in rats following intragastric instillation of SWCNT at a concentration of $0.64 \mathrm{mg} / \mathrm{kg}$ body weight. SWCNTs were demonstrated to elevate the levels of 8-oxodG in liver and lung tissues of rats. The length and width of the nanoparticles was less than $1 \mu \mathrm{m}$ and 0.9-1.7 nm, respectively [98]. The aortic mitochondrial alteration was studied using oxidative stress assays in SWCNTs exposed C57BL/6 mice. The intra-pharyngeal instilled SWCNTs $(40 \mu \mathrm{g} / \mathrm{mouse})$ activated heme oxygenase 1 , which is indicative of oxidative stress. The nanoparticles exhibited increased mitochondrial DNA damage accompanied by the changes in aortic mitochondrial protein carbonyl and glutathione levels [112].

The general toxicity effects of MWCNTs were inflammation, granuloma and fibrosis when in vivo toxicity measurements were performed in experimental animals [103,104,106]. The induction of mesothelioma in p53+/- mouse was studied by the intraperitoneal application of multi-wall carbon nanotube. It was found that intraperitoneally administered, micro-sized MWCNTs (10-20 $\mu \mathrm{m})$ stimulated mesothelioma such as the positive control, crocidolite [113]. The immune and inflammatory responses of MWCNTs were tested following intraperitoneal administration of a single dose of $2 \mathrm{mg} / \mathrm{kg}$ body weight to female ICR mice. After 1 week of post-exposure, the expression of leukocyte adhesion molecules and cluster of differentiation on granulocytes were found increased. The number of monocytes, leukocytes, and granulocytes were also present in peripheral blood significantly. MWCNTs were reported to exhibit sustained immune responses with the overexpressed ovalbumin specific IgG1 and IgM. The original morphology of the liver had also suffered changes to a rounded shape along with the appearance of MWCNTs on internal organs [114].

\section{Conclusions and Perspectives}

In this review, we have discussed the toxicity effects of $0-\mathrm{D}$ and $1-\mathrm{D}$ carbon nanomaterials in different cell lines and animal models. It was demonstrated that differential toxicity of carbon nanomaterials was inherited from various factors such as size, dispersion, cell permeability, and functionalization. Though the researchers studied the toxicity of carbon nanomaterials in both in vitro and in vivo intensively, there are still some issues to be addressed. (1) Many researchers showed experimental results with the aim of comparing the toxicity of two or more carbon-based nanoparticles for the same cell line and animal model. A comparative study is required for different cell line sources and animal species for the same kind of nanoparticle. (2) There are many studies that emphasize the role of the encapsulating agents on the nanoparticles in altering the overall functionality. The differential toxicity depending on the charge on the surface of nanoparticles has also been demonstrated. However, a systematic study is needed to corroborate the toxicity results with the surface charge of the nanoparticles (either positive or negative) with subtle differences. (3) The toxicity studies of the same kind of carbon nanoparticle prepared from different techniques should also be examined. The following suggestions are put forth for future research in this field: (1) A comprehensive study on the toxicity of carbon nanomaterials using different physicochemical and biological parameters to exemplify toxicity limitation and prove the effectiveness of the materials. (2) A systematic study to ensure that the carbon nanoparticles exhibit toxicity towards cancerous cells but not normal cells at the established concentration range. Undoubtedly, the knowledge of the toxicity of carbon nanomaterials will help the researchers with interdisciplinary backgrounds to deliver more successful biocompatible materials to society in the future. 
Author Contributions: I.-S.R. and D.-W.H. developed the idea and structure of the review article. I.S.R. and S.J.S. wrote the paper using the materials supplied by M.S.K., Y.B.L., B.K., S.W.H., and S.J.J., J.-C.L. revised and improved the manuscript. D.W.H. supervised the manuscript. All the authors have given approval to the final version of the manuscript.

Funding: This research was supported by the Bio \& Medical Technology Development Program of the National Research Foundation (NRF) funded by the Korean government (MEST, No. 2015M3A9E2028643), Ministry of Trade, Industry and Energy (MOTIE, Korea, No. N0002310 and Technology Innovation Program No. 20000397), and Korea Research Institute of Chemical Technology (KRICT, Daejeon and Ulsan, Korea) and Ulsan City (SI1941-20, BS.K19-251)

Conflicts of Interest: The authors declare no conflict of interest.

\section{References}

1. Raza, M.A.; Kanwal, Z.; Rauf, A.; Sabri, A.N.; Riaz, S.; Naseem, S. Size- and Shape-Dependent Antibacterial Studies of Silver Nanoparticles Synthesized by Wet Chemical Routes. Nanomaterials 2016, 6, 74. [CrossRef]

2. Han, X.; Li, S.; Peng, Z.; Al-Yuobi, A.O.; Bashammakh, A.S.O.; El-Shahawi, M.S.; Leblanc, R.M. Interactions between Carbon Nanomaterials and Biomolecules. J. Oleo Sci. 2016, 65, 1-7. [CrossRef]

3. Cacciotti, I.; Chronopoulou, L.; Palocci, C.; Amalfitano, A.; Cantiani, M.; Cordaro, M.; Lajolo, C.; Callà, C.; Boninsegna, A.; Lucchetti, D.; et al. Controlled release of $18-\beta$-glycyrrhetic acid by nanodelivery systems increases cytotoxicity on oral carcinoma cell line. Nanotechnology 2018, 29, 285101. [CrossRef]

4. Ramos, A.P.; Cruz, M.A.E.; Tovani, C.B.; Ciancaglini, P. Biomedical applications of nanotechnology. Biophys. Rev. 2017, 9, 79-89. [CrossRef]

5. Reddy, L.H.; Arias, J.L.; Nicolas, J.; Couvreur, P. Magnetic Nanoparticles: Design and Characterization, Toxicity and Biocompatibility, Pharmaceutical and Biomedical Applications. Chem. Rev. 2012, 112, 5818-5878. [CrossRef]

6. Zhu, S.; Gong, L.; Xie, J.; Gu, Z.; Zhao, Y. Design, Synthesis, and Surface Modification of Materials Based on Transition-Metal Dichalcogenides for Biomedical Applications. Small Methods 2017, 1, 1700220. [CrossRef]

7. Cha, C.; Shin, S.R.; Annabi, N.; Dokmeci, M.R.; Khademhosseini, A. Carbon-Based Nanomaterials: Multifunctional Materials for Biomedical Engineering. ACS Nano 2013, 7, 2891-2897. [CrossRef]

8. Hong, W.; Liu, Y.; Li, M.H.; Xing, Y.X.; Chen, T.; Fu, Y.H.; Jiang, L.; Zhao, H.; Jia, A.Q.; Wang, J.-S. In vivo toxicology of carbon dots by 1H NMR-based metabolomics. Toxicol. Res. 2018, 7, 834-847. [CrossRef]

9. Xiao, Y.Y.; Liu, L.; Chen, Y.; Zeng, Y.L.; Liu, M.Z.; Jin, L. Developmental Toxicity of Carbon Quantum Dots to the Embryos/Larvae of Rare Minnow (Gobiocypris rarus). BioMed Res. Int. 2016, 2016, 1-11. [CrossRef]

10. Xu, Y.; Tang, C.J.; Huang, H.; Sun, C.Q.; Zhang, Y.K.; Ye, Q.F.; Wang, A.J. Green Synthesis of Fluorescent Carbon Quantum Dots for Detection of $\mathrm{Hg}^{2+}$. Chin. J. Anal. Chem. 2014, 42, 1252-1258. [CrossRef]

11. Cayuela, A.; Soriano, M.L.; Carrion, C.C.; Valcárcel, M. Semiconductor and carbon-based fluorescent nanodots: The need for consistency. Chem. Commun. 2016, 52, 1311-1326. [CrossRef] [PubMed]

12. Cole, I.S.; Wang, D.S.; Li, Q. The toxicity of graphene quantum dots. RSC Adv. 2016, 6, 89867-89878.

13. Zhang, X.; Yin, J.; Kang, C.; Li, J.; Zhu, Y.; Li, W.; Huang, Q.; Zhu, Z. Biodistribution and toxicity of nanodiamonds in mice after intratracheal instillation. Toxicol. Lett. 2010, 198, 237-243. [CrossRef] [PubMed]

14. Lin, Y.C.; Wu, K.T.; Lin, Z.R.; Perevedentseva, E.; Karmenyan, A.; Lin, M.D.; Cheng, C.L.; Lin, Y.; Wu, K.; Cheng, C. Nanodiamond for biolabelling and toxicity evaluation in the zebrafish embryoin vivo. J. Biophotonics 2016, 9, 827-836. [CrossRef]

15. Silbajoris, R.; Linak, W.; Shenderova, O.; Winterrowd, C.; Chang, H.-C.; Zweier, J.L.; Kota, A.; Dailey, L.A.; Nunn, N.; Bromberg, P.A.; et al. Detonation nanodiamond toxicity in human airway epithelial cells is modulated by air oxidation. Diam. Relat. Mater. 2015, 58, 16-23. [CrossRef]

16. Chaudhuri, I.; Fruijtier-Polloth, C.; Ngiewih, Y.; Levy, L. Evaluating the evidence on genotoxicity and reproductive toxicity of carbon black: A critical review. Crit. Rev. Toxicol. 2018, 48, 143-169. [CrossRef]

17. Jackson, P.; Hougaard, K.S.; Boisen, A.M.Z.; Jacobsen, N.R.; Jensen, K.A.; Møller, P.; Brunborg, G.; Gützkow, K.B.; Andersen, O.; Loft, S.; et al. Pulmonary exposure to carbon black by inhalation or instillation in pregnant mice: Effects on liver DNA strand breaks in dams and offspring. Nanotoxicology 2012, 6, 486-500. [CrossRef] [PubMed] 
18. Husain, M.; Kyjovska, Z.O.; Bourdon-Lacombe, J.; Saber, A.T.; Jensen, K.A.; Jacobsen, N.R.; Williams, A.; Wallin, H.; Halappanavar, S.; Vogel, U.; et al. Carbon black nanoparticles induce biphasic gene expression changes associated with inflammatory responses in the lungs of C57BL/6 mice following a single intratracheal instillation. Toxicol. Appl. Pharmacol. 2015, 289, 573-588. [CrossRef]

19. Gray, C.A.; Muranko, H. Studies of Robustness of Industrial Aciniform Aggregates and Agglomerates-Carbon Black and Amorphous Silicas: A Review Amplified by New Data. J. Occup. Environ. Med. 2006, 48, 1279-1290. [CrossRef]

20. Watson, A.Y.; Valberg, P.A. Carbon Black and Soot: Two Different Substances. AIHA J. 2001, 62, $218-228$. [CrossRef]

21. Zhang, W.; Liu, Q.; Chen, P. Flexible Strain Sensor Based on Carbon Black/Silver Nanoparticles Composite for Human Motion Detection. Materials 2018, 11, 1836. [CrossRef]

22. Mazzaracchio, V.; Tomei, M.R.; Cacciotti, I.; Chiodoni, A.; Novara, C.; Castellino, M.; Scordo, G.; Amine, A.; Moscone, D.; Arduini, F. Inside the different types of carbon black as nanomodifiers for screen-printed electrodes. Electrochim. Acta 2019, 317, 673-683. [CrossRef]

23. Johnston, H.J.; Hutchison, G.R.; Christensen, F.M.; Aschberger, K.; Stone, V. The biological mechanisms and physicochemical characteristics responsible for driving fullerene toxicity. Toxicol. Sci. 2010, 114, 162-182. [CrossRef]

24. Nielsen, G.D.; Roursgaard, M.; Jensen, K.A.; Poulsen, S.S.; Larsen, S.T. In vivoBiology and Toxicology of Fullerenes and Their Derivatives. Basic Clin. Pharmacol. Toxicol. 2008, 103, 197-208. [CrossRef]

25. Aschberger, K.; Johnston, H.J.; Stone, V.; Aitken, R.J.; Tran, C.L.; Hankin, S.M.; Peters, S.A.; Christensen, F.M. Review of fullerene toxicity and exposure-Appraisal of a human health risk assessment, based on open literature. Regul. Toxicol. Pharmacol. 2010, 58, 455-473. [CrossRef]

26. Mori, T.; Takada, H.; Ito, S.; Matsubayashi, K.; Miwa, N.; Sawaguchi, T. Preclinical studies on safety of fullerene upon acute oral administration and evaluation for no mutagenesis. Toxicology 2006, 225, 48-54. [CrossRef]

27. Mrđanović, J.; Solajic, S.; Bogdanovic, V.; Stankov, K.; Bogdanovic, G.; Djordjevic, A. Effects of fullerenol $\mathrm{C}_{60}(\mathrm{OH})_{24}$ on the frequency of micronuclei and chromosome aberrations in CHO-K1 cells. Mutat. Res. Toxicol. Environ. Mutagen. 2009, 680, 25-30. [CrossRef]

28. Antunes, M.; Velasco, J.I. Multifunctional polymer foams with carbon nanoparticles. Prog. Polym. Sci. 2014, 39, 486-509. [CrossRef]

29. Tong, C.W.; Berawi, M.A.; Khalil, M.; Jan, B.M. Advanced nanomaterials in oil and gas industry: Design, application and challenges. Appl. Energy 2017, 191, 287-310.

30. Wu, D.; Wu, L.; Zhou, W.; Sun, Y.; Zhang, M. Relations between the aspect ratio of carbon nanotubes and the formation of percolation networks in biodegradable polylactide/carbon nanotube composites. J. Polym. Sci. Part B Polym. Phys. 2010, 48, 479-489. [CrossRef]

31. Ando, Y.; Zhao, X.; Sugai, T.; Kumar, M. Growing carbon nanotubes. Mater. Today 2004, 7, 22-29. [CrossRef]

32. Francis, A.P.; Ganapathy, S.; Palla, V.R.; Murthy, P.B.; Ramaprabhu, S.; Devasena, T. One time nose-only inhalation of MWCNTs: Exploring the mechanism of toxicity by intermittent sacrifice in Wistar rats. Toxicol. Rep. 2015, 2, 111-120. [CrossRef] [PubMed]

33. Kobayashi, N.; Izumi, H.; Morimoto, Y. Review of toxicity studies of carbon nanotubes. J. Occup. Health 2017, 59, 394-407. [CrossRef] [PubMed]

34. Ema, M.; Gamo, M.; Honda, K. A review of toxicity studies of single-walled carbon nanotubes in laboratory animals. Regul. Toxicol. Pharmacol. 2016, 74, 42-63. [CrossRef] [PubMed]

35. Mohanta, D.; Patnaik, S.; Sood, S.; Das, N. Carbon nanotubes: Evaluation of toxicity at biointerfaces. J. Pharm. Anal. 2019. [CrossRef]

36. Singh, E.; Srivastava, R.; Kumar, U.; Katheria, A.D. Carbon nanotube: A review on introduction, fabrication techniques and optical applications. Nanosci. Nanotechnol. Res. 2017, 4, 120-126.

37. Vlasova, I.I.; Sokolov, A.V.; Chekanov, A.V.; Kostevich, V.A.; Vasilyev, V.B. Myeloperoxidase-induced biodegradation of single-walled carbon nanotubes is mediated by hypochlorite. Russ. J. Bioorganic Chem. 2011, 37, 453-463. [CrossRef]

38. Tasis, D.; Tagmatarchis, N.; Bianco, A.; Prato, M. Chemistry of Carbon Nanotubes. Chem. Rev. 2006, 106, 1105-1136. [CrossRef] 
39. Park, E.J.; Zahari, N.E.M.; Kang, M.S.; Lee, S.J.; Lee, K.; Lee, B.S.; Yoon, C.; Cho, M.H.; Kim, Y.; Kim, J.H. Toxic response of HIPCO single-walled carbon nanotubes in mice and RAW264.7 macrophage cells. Toxicol. Lett. 2014, 229, 167-177. [CrossRef]

40. Chou, C.C.; Hsiao, H.Y.; Hong, Q.S.; Chen, C.H.; Peng, Y.W.; Chen, H.W.; Yang, P.C. Single-Walled Carbon Nanotubes Can Induce Pulmonary Injury in Mouse Model. Nano Lett. 2008, 8, 437-445. [CrossRef]

41. Al Faraj, A.; Bessaad, A.; Cieślar, K.; Lacroix, G.; Canet-Soulas, E.; Crémillieux, Y. Long-term follow-up of lung biodistribution and effect of instilled SWCNTs using multiscale imaging techniques. Nanotechnology 2010, 21, 175103. [CrossRef] [PubMed]

42. Shvedova, A.A.; Kisin, E.R.; Murray, A.R.; Gorelik, O.; Arepalli, S.; Castranova, V.; Young, S.-H.; Gao, F.; Tyurina, Y.Y.; Oury, T.D.; et al. Vitamin E Deficiency Enhances Pulmonary Inflammatory Response and Oxidative Stress Induced by Single Walled Carbon Nanotubes in C57BL/6 Mice. Toxicol. Appl. Pharmacol. 2007, 221, 339-348. [CrossRef] [PubMed]

43. Wang, L.; Castranova, V.; Mishra, A.; Chen, B.; Mercer, R.R.; Schwegler-Berry, D.; Rojanasakul, Y. Dispersion of single-walled carbon nanotubes by a natural lung surfactant for pulmonary in vitro and in vivo toxicity studies. Part. Fibre Toxicol. 2010, 7, 31. [CrossRef] [PubMed]

44. Catalán, J.; Siivola, K.M.; Nymark, P.; Lindberg, H.K.; Suhonen, S.; Järventaus, H.; Koivisto, A.J.; Moreno, C.; Vanhala, E.; Wolff, H.; et al. In vitro and in vivo genotoxic effects of straight versus tangled multi-walled carbon nanotubes. Nanotoxicology 2016, 10,1-47. [CrossRef] [PubMed]

45. Rittinghausen, S.; Hackbarth, A.; Creutzenberg, O.; Ernst, H.; Heinrich, U.; Leonhardt, A.; Schaudien, D. The carcinogenic effect of various multi-walled carbon nanotubes (MWCNTs) after intraperitoneal injection in rats. Part. Fibre Toxicol. 2014, 11, 59. [CrossRef] [PubMed]

46. Emam, A.N.; Loutfy, S.A.; Mostafa, A.A.; Awad, H.; Mohamed, M.B. Cyto-toxicity, biocompatibility and cellular response of carbon dots-plasmonic based nano-hybrids for bioimaging. RSC Adv. 2017, 7, 23502-23514. [CrossRef]

47. Zhang, X.; He, X.; Li, Y.; Zhang, Z.; Ma, Y.; Li, F.; Liu, J. A cytotoxicity study of fluorescent carbon nanodots using human bronchial epithelial cells. J. Nanosci. Nanotechnol. 2013, 13, 5254-5259. [CrossRef] [PubMed]

48. Havrdova, M.; Hola, K.; Skopalik, J.; Tomankova, K.; Petr, M.; Cepe, K.; Polakova, K.; Tucek, J.; Bourlinos, A.B.; Zboril, R. Toxicity of carbon dots-Effect of surface functionalization on the cell viability, reactive oxygen species generation and cell cycle. Carbon 2016, 99, 238-248. [CrossRef]

49. Zhu, S.; Zhang, J.; Qiao, C.; Tang, S.; Li, Y.; Yuan, W.; Li, B.; Tian, L.; Liu, F.; Hu, R.; et al. Strongly green-photoluminescent graphene quantum dots for bioimaging applications. Chem. Commun. 2011, 47, 6858-6860. [CrossRef] [PubMed]

50. Tian, X.; Xiao, B.-B.; Wu, A.; Yu, L.; Zhou, J.; Wang, Y.; Wang, N.; Guan, H.; Shang, Z.-F. Hydroxylated-graphene quantum dots induce cells senescence in both p53-dependent and -independent manner. Toxicol. Res. 2016, 5, 1639-1648. [CrossRef] [PubMed]

51. Wu, C.; Wang, C.; Han, T.; Zhou, X.; Guo, S.; Zhang, J. Insight into the Cellular Internalization and Cytotoxicity of Graphene Quantum Dots. Adv. Health Mater. 2013, 2, 1613-1619. [CrossRef] [PubMed]

52. Xing, Y.; Xiong, W.; Zhu, L.; Osawa, E.; Hussin, S.; Dai, L. DNA Damage in Embryonic Stem Cells Caused by Nanodiamonds. ACS Nano 2011, 5, 2376-2384. [CrossRef] [PubMed]

53. Horie, M.; Komaba, L.K.; Kato, H.; Nakamura, A.; Yamamoto, K.; Endoh, S.; Fujita, K.; Kinugasa, S.; Mizuno, K.; Hagihara, Y.; et al. Evaluation of cellular influences induced by stable nanodiamond dispersion; the cellular influences of nanodiamond are small. Diam. Relat. Mater. 2012, 24, 15-24. [CrossRef]

54. Thomas, V.; Halloran, B.A.; Ambalavanan, N.; Catledge, S.A.; Vohra, Y.K. In vitro studies on the effect of particle size on macrophage responses to nanodiamond wear debris. Acta Biomater. 2012, 8, 1939-1947. [CrossRef] [PubMed]

55. Puzyr, A.; Neshumayev, D.; Tarskikh, S.; Makarskaya, G.; Dolmatov, V.; Bondar, V. Destruction of human blood cells in interaction with detonation nanodiamonds in experiments in vitro. Diam. Relat. Mater. 2004, 13, 2020-2023. [CrossRef]

56. Dworak, N.; Wnuk, M.; Zebrowski, J.; Bartosz, G.; Lewinska, A. Genotoxic and mutagenic activity of diamond nanoparticles in human peripheral lymphocytes in vitro. Carbon 2014, 68, 763-776. [CrossRef]

57. Solarska, K.; Gajewska, A.; Kaczorowski, W.; Bartosz, G.; Mitura, K. Effect of nanodiamond powders on the viability and production of reactive oxygen and nitrogen species by human endothelial cells. Diam. Relat. Mater. 2012, 21, 107-113. [CrossRef] 
58. Marcon, L.; Riquet, F.; Vicogne, D.; Szunerits, S.; Bodart, J.-F.; Boukherroub, R. Cellular and in vivo toxicity of functionalized nanodiamond in Xenopus embryos. J. Mater. Chem. 2010, 20, 8064-8069. [CrossRef]

59. Stone, V.; Shaw, J.; Brown, D.; MacNee, W.; Faux, S.; Donaldson, K. The role of oxidative stress in the prolonged inhibitory effect of ultrafine carbon black on epithelial cell function. Toxicol. Vitr. 1998, 12, 649-659. [CrossRef]

60. Vesterdal, L.K.; Danielsen, P.H.; Folkmann, J.K.; Jespersen, L.F.; Aguilar-Pelaez, K.; Roursgaard, M.; Loft, S.; Møller, P. Accumulation of lipids and oxidatively damaged DNA in hepatocytes exposed to particles. Toxicol. Appl. Pharmacol. 2014, 274, 350-360. [CrossRef]

61. Jacobsen, N.R.; Saber, A.T.; White, P.; Møller, P.; Pojana, G.; Vogel, U.; Loft, S.; Gingerich, J.; Soper, L.; Douglas, G.R.; et al. Increased mutant frequency by carbon black, but not quartz, in thelacZ andcII transgenes of muta ${ }^{\mathrm{TM}}$ mouse lung epithelial cells. Environ. Mol. Mutagen. 2007, 48, 451-461. [CrossRef] [PubMed]

62. Tamaoki, J.; Isono, K.; Takeyama, K.; Tagaya, E.; Nakata, J.; Nagai, A. Ultrafine carbon black particles stimulate proliferation of human airway epithelium via EGF receptor-mediated signaling pathway. Am. J. Physiol. Cell. Mol. Physiol. 2004, 287, L1127-L1133. [CrossRef] [PubMed]

63. Di Giorgio, M.L.; Di Bucchianico, S.; Ragnelli, A.M.; Aimola, P.; Santucci, S.; Poma, A. Effects of single and multi walled carbon nanotubes on macrophages: Cyto and genotoxicity and electron microscopy. Mutat. Res. Toxicol. Environ. Mutagen. 2011, 722, 20-31. [CrossRef] [PubMed]

64. Mroz, R.M.; Schins, R.P.F.; Li, H.; Drost, E.M.; MacNee, W.; Donaldson, K. Nanoparticle carbon black driven DNA damage induces growth arrest and AP-1 and NFkappaB DNA binding in lung epithelial A549 cell line. J. Physiol. Pharmacol. 2007, 58, 467-470.

65. Cao, Y.; Roursgaard, M.; Danielsen, P.H.; Møller, P.; Loft, S. Carbon Black Nanoparticles Promote Endothelial Activation and Lipid Accumulation in Macrophages Independently of Intracellular ROS Production. PLoS ONE 2014, 9, e106711. [CrossRef] [PubMed]

66. Jacobsen, N.R.; Pojana, G.; White, P.; Møller, P.; Cohn, C.A.; Korsholm, K.S.; Vogel, U.; Marcomini, A.; Loft, S.; Wallin, H. Genotoxicity, cytotoxicity, and reactive oxygen species induced by single-walled carbon nanotubes and $\mathrm{C}_{60}$ fullerenes in the FE1-Muta ${ }^{\mathrm{TM} M o u s e}$ lung epithelial cells. Environ. Mol. Mutagen. 2008, 49, 476-487. [CrossRef]

67. Totsuka, Y.; Higuchi, T.; Imai, T.; Nishikawa, A.; Nohmi, T.; Kato, T.; Masuda, S.; Kinae, N.; Hiyoshi, K.; Ogo, S.; et al. Genotoxicity of nano/microparticles in in vitro micronuclei, in vivo comet and mutation assay systems. Part. Fibre Toxicol. 2009, 6, 23. [CrossRef]

68. Dhawan, A.; Taurozzi, J.S.; Pandey, A.K.; Shan, W.; Miller, S.M.; Hashsham, S.A.; Tarabara, V.V. Stable Colloidal Dispersions of $\mathrm{C}_{60}$ Fullerenes in Water: Evidence for Genotoxicityt. Environ. Sci. Technol. 2006, 40, 7394-7401. [CrossRef]

69. Yamawaki, H.; Iwai, N. Cytotoxicity of water-soluble fullerene in vascular endothelial cells. Am. J. Physiol. Physiol. 2006, 290, C1495-C1502. [CrossRef]

70. Cui, D.; Tian, F.; Ozkan, C.S.; Wang, M.; Gao, H. Effect of single wall carbon nanotubes on human HEK293 cells. Toxicol. Lett. 2005, 155, 73-85. [CrossRef]

71. Wick, P.; Manser, P.; Limbach, L.K.; Dettlaff-Weglikowska, U.; Krumeich, F.; Roth, S.; Stark, W.J.; Bruinink, A. The degree and kind of agglomeration affect carbon nanotube cytotoxicity. Toxicol. Lett. 2007, 168, 121-131. [CrossRef] [PubMed]

72. Jia, G.; Wang, H.; Yan, L.; Wang, X.; Pei, R.; Yan, T.; Zhao, Y.; Guo, X. Cytotoxicity of Carbon Nanomaterials: Single-Wall Nanotube, Multi-Wall Nanotube, and Fullerene. Environ. Sci. Technol. 2005, 39, 1378-1383. [CrossRef]

73. Pantarotto, D.; Briand, J.P.; Prato, M.; Bianco, A. Translocation of bioactive peptides across cell membranes by carbon nanotubes. Chem. Commun. 2004, 16-17. [CrossRef] [PubMed]

74. Shvedova, A.; Castranova, V.; Kisin, E.; Schwegler-Berry, D.; Murray, A.; Gandelsman, V.; Maynard, A.; Baron, P. Exposure to Carbon Nanotube Material: Assessment of Nanotube Cytotoxicity using Human Keratinocyte Cells. J. Toxicol. Environ. Health Part A 2003, 66, 1909-1926. [CrossRef] [PubMed]

75. Francis, A.P.; Devasena, T. Toxicity of carbon nanotubes: A review. Toxicol. Ind. Health 2018, 34, $200-210$. [CrossRef] [PubMed]

76. Sayes, C.M.; Liang, F.; Hudson, J.L.; Mendez, J.; Guo, W.; Beach, J.M.; Moore, V.C.; Doyle, C.D.; West, J.L.; Billups, W.E.; et al. Functionalization density dependence of single-walled carbon nanotubes cytotoxicity in vitro. Toxicol. Lett. 2006, 161, 135-142. [CrossRef] [PubMed] 
77. Pacurari, M.; Yin, X.J.; Zhao, J.; Ding, M.; Leonard, S.S.; Schwegler-Berry, D.; Ducatman, B.S.; Sbarra, D.; Hoover, M.D.; Castranova, V.; et al. Raw Single-Wall Carbon Nanotubes Induce Oxidative Stress and Activate MAPKs, AP-1, NF-кB, and Akt in Normal and Malignant Human Mesothelial Cells. Environ. Health Perspect. 2008, 116, 1211-1217. [CrossRef]

78. Kisin, E.R.; Murray, A.R.; Keane, M.J.; Shi, X.-C.; Schwegler-Berry, D.; Gorelik, O.; Arepalli, S.; Castranova, V.; Wallace, W.E.; Kagan, V.E.; et al. Single-walled Carbon Nanotubes: Geno- and Cytotoxic Effects in Lung Fibroblast V79 Cells. J. Toxicol. Environ. Health Part A 2007, 70, 2071-2079.

79. Hirano, S.; Kanno, S.; Furuyama, A. Multi-walled carbon nanotubes injure the plasma membrane of macrophages. Toxicol. Appl. Pharmacol. 2008, 232, 244-251. [CrossRef]

80. Monteiro-Riviere, N.A.; Nemanich, R.J.; Inman, A.O.; Wang, Y.Y.; Riviere, J.E. Multi-walled carbon nanotube interactions with human epidermal keratinocytes. Toxicol. Lett. 2005, 155, 377-384. [CrossRef]

81. Ding, L.; Stilwell, J.; Zhang, T.; Elboudwarej, O.; Jiang, H.; Selegue, J.P.; Cooke, P.A.; Gray, J.W.; Chen, F.F. Molecular Characterization of the Cytotoxic Mechanism of Multiwall Carbon Nanotubes and Nano-Onions on Human Skin Fibroblast. Nano Lett. 2005, 5, 2448-2464. [CrossRef] [PubMed]

82. Bottini, M.; Bruckner, S.; Nika, K.; Bottini, N.; Bellucci, S.; Magrini, A.; Bergamaschi, A.; Mustelin, T. Multi-walled carbon nanotubes induce T lymphocyte apoptosis. Toxicol. Lett. 2006, 160, 121-126. [CrossRef] [PubMed]

83. Yao, K.; Lv, X.; Zheng, G.; Chen, Z.; Jiang, Y.; Zhu, X.; Wang, Z.; Cai, Z. Effects of Carbon Quantum Dots on Aquatic Environments: Comparison of Toxicity to Organisms at Different Trophic Levels. Environ. Sci. Technol. 2018, 52, 14445-14451. [CrossRef] [PubMed]

84. Zheng, X.; Shao, D.; Li, J.; Song, Y.; Chen, Y.; Pan, Y.; Zhu, S.; Yang, B.; Chen, L. Single and repeated dose toxicity of citric acid-based carbon dots and a derivative in mice. RSC Adv. 2015, 5, 91398-91406. [CrossRef]

85. Jiang, D.; Chen, Y.; Li, N.; Li, W.; Wang, Z.; Zhu, J.; Zhang, H.; Liu, B.; Xu, S. Synthesis of Luminescent Graphene Quantum Dots with High Quantum Yield and Their Toxicity Study. PLoS ONE 2015, 10, e0144906. [CrossRef] [PubMed]

86. Wang, Z.G.; Zhou, R.; Jiang, D.; Song, J.E.; Xu, Q.; Si, J.; Chen, Y.P.; Zhou, X.; Gan, L.; Li, J.Z.; et al. Toxicity of Graphene Quantum Dots in Zebrafish Embryo. Biomed. Environ. Sci. 2015, 28, 341-351. [PubMed]

87. Chong, Y.; Ma, Y.; Shen, H.; Tu, X.; Zhou, X.; Xu, J.; Dai, J.; Fan, S.; Zhang, Z. The in vitro and in vivo toxicity of graphene quantum dots. Biomaterials 2014, 35, 5041-5048. [CrossRef] [PubMed]

88. Nurunnabi, M.; Khatun, Z.; Huh, K.M.; Park, S.Y.; Lee, D.Y.; Cho, K.J.; Lee, Y.K. In Vivo Biodistribution and Toxicology of Carboxylated Graphene Quantum Dots. ACS Nano 2013, 7, 6858-6867. [CrossRef] [PubMed]

89. Mohan, N.; Chen, C.S.; Hsieh, H.H.; Wu, Y.C.; Chang, H.C. In Vivo Imaging and Toxicity Assessments of Fluorescent Nanodiamonds inCaenorhabditis elegans. Nano Lett. 2010, 10, 3692-3699. [CrossRef]

90. Yuan, Y.; Wang, X.; Jia, G.; Liu, J.H.; Wang, T.; Gu, Y.; Yang, S.T.; Zhen, S.; Wang, H.; Liu, Y. Pulmonary toxicity and translocation of nanodiamonds in mice. Diam. Relat. Mater. 2010, 19, 291-299. [CrossRef]

91. Kamata, H.; Tasaka, S.; Inoue, K.I.; Miyamoto, K.; Nakano, Y.; Shinoda, H.; Kimizuka, Y.; Fujiwara, H.; Ishii, M.; Hasegawa, N.; et al. Carbon black nanoparticles enhance bleomycin-induced lung inflammatory and fibrotic changes in mice. Exp. Biol. Med. 2011, 236, 315-324. [CrossRef] [PubMed]

92. Inoue, K.-I.; Yanagisawa, R.; Koike, E.; Nakamura, R.; Ichinose, T.; Tasaka, S.; Kiyono, M.; Takano, H. Effects of Carbon Black Nanoparticles on Elastase-Induced Emphysematous Lung Injury in Mice. Basic Clin. Pharmacol. Toxicol. 2011, 108, 234-240. [CrossRef] [PubMed]

93. Saputra, D.; Yoon, J.H.; Park, H.; Heo, Y.; Yang, H.; Lee, E.J.; Lee, S.; Song, C.W.; Lee, K. Inhalation of Carbon Black Nanoparticles Aggravates Pulmonary Inflammation in Mice. Toxicol. Res. 2014, 30, 83-90. [CrossRef] [PubMed]

94. Lindner, K.; Ströbele, M.; Schlick, S.; Webering, S.; Jenckel, A.; Kopf, J.; Danov, O.; Sewald, K.; Buj, C.; Creutzenberg, O.; et al. Biological effects of carbon black nanoparticles are changed by surface coating with polycyclic aromatic hydrocarbons. Part. Fibre Toxicol. 2017, 14, 8. [CrossRef] [PubMed]

95. Morimoto, Y.; Hirohashi, M.; Ogami, A.; Oyabu, T.; Myojo, T.; Nishi, K.-I.; Kadoya, C.; Todoroki, M.; Yamamoto, M.; Murakami, M.; et al. Inflammogenic effect of well-characterized fullerenes in inhalation and intratracheal instillation studies. Part. Fibre Toxicol. 2010, 7, 4. [CrossRef] [PubMed] 
96. Fujita, K.; Morimoto, Y.; Ogami, A.; Myojyo, T.; Tanaka, I.; Shimada, M.; Wang, W.-N.; Endoh, S.; Uchida, K.; Nakazato, T.; et al. Gene expression profiles in rat lung after inhalation exposure to $\mathrm{C}_{60}$ fullerene particles. Toxicology 2009, 258, 47-55. [CrossRef] [PubMed]

97. Park, E.J.; Kim, H.; Kim, Y.; Yi, J.; Choi, K.; Park, K. Carbon fullerenes $\left(\mathrm{C}_{60} \mathrm{~s}\right)$ can induce inflammatory responses in the lung of mice. Toxicol. Appl. Pharmacol. 2010, 244, 226-233. [CrossRef] [PubMed]

98. Folkmann, J.K.; Risom, L.; Jacobsen, N.R.; Wallin, H.; Loft, S.; Møller, P. Oxidatively damaged DNA in rats exposed by oral gavage to $\mathrm{C}_{60}$ fullerenes and single-walled carbon nanotubes. Environ. Health Perspect. 2009, 117, 703-708. [CrossRef]

99. Roursgaard, M.; Poulsen, S.S.; Kepley, C.L.; Hammer, M.; Nielsen, G.D.; Larsen, S.T. Polyhydroxylated $\mathrm{C}_{60}$ Fullerene (Fullerenol) Attenuates Neutrophilic Lung Inflammation in Mice. Basic Clin. Pharmacol. Toxicol. 2008, 103, 386-388. [CrossRef]

100. Kagan, V.E.; Konduru, N.V.; Feng, W.; Allen, B.L.; Conroy, J.; Volkov, Y.; Vlasova, I.I.; Belikova, N.A.; Yanamala, N.; Kapralov, A.; et al. Carbon nanotubes degraded by neutrophil myeloperoxidase induce less pulmonary inflammation. Nat. Nanotechnol. 2010, 5, 354-359. [CrossRef]

101. Lin, Z.; Ma, L.; Zhu-Ge, X.; Zhang, H.; Lin, B. A comparative study of lung toxicity in rats induced by three types of nanomaterials. Nanoscale Res. Lett. 2013, 8, 521. [CrossRef] [PubMed]

102. Saber, A.T.; Lamson, J.S.; Jacobsen, N.R.; Ravn-Haren, G.; Hougaard, K.S.; Nyendi, A.N.; Wahlberg, P.; Madsen, A.M.; Jackson, P.; Wallin, H.; et al. Particle-Induced Pulmonary Acute Phase Response Correlates with Neutrophil Influx Linking Inhaled Particles and Cardiovascular Risk. PLoS ONE 2013, 8, e69020. [CrossRef] [PubMed]

103. Poland, C.A.; Duffin, R.; Kinloch, I.; Maynard, A.; Wallace, W.A.H.; Seaton, A.; Stone, V.; Brown, S.; MacNee, W.; Donaldson, K. Carbon nanotubes introduced into the abdominal cavity of mice show asbestos-like pathogenicity in a pilot study. Nat. Nanotechnol. 2008, 3, 423-428. [CrossRef] [PubMed]

104. Morimoto, Y.; Hirohashi, M.; Ogami, A.; Oyabu, T.; Myojo, T.; Todoroki, M.; Yamamoto, M.; Hashiba, M.; Mizuguchi, Y.; Lee, B.W.; et al. Pulmonary toxicity of well-dispersed multi-wall carbon nanotubes following inhalation and intratracheal instillation. Nanotoxicology 2012, 6, 587-599. [CrossRef] [PubMed]

105. Muller, J.; Huaux, F.; Moreau, N.; Misson, P.; Heilier, J.-F.; Delos, M.; Arras, M.; Fonseca, A.; Nagy, J.B.; Lison, D. Respiratory toxicity of multi-wall carbon nanotubes. Toxicol. Appl. Pharmacol. 2005, 207, 221-231. [CrossRef] [PubMed]

106. Grubek-Jaworska, H.; Nejman, P.; Czumińska, K.; Przybyłowski, T.; Huczko, A.; Lange, H.; Bystrzejewski, M.; Baranowski, P.; Chazan, R. Preliminary results on the pathogenic effects of intratracheal exposure to one-dimensional nanocarbons. Carbon 2006, 44, 1057-1063. [CrossRef]

107. Boisen, A.M.Z.; Shipley, T.; Jackson, P.; Wallin, H.; Nellemann, C.; Vogel, U.; Yauk, C.L.; Hougaard, K.S. In utero exposure to nanosized carbon black (Printex90) does not induce tandem repeat mutations in female murine germ cells. Reprod. Toxicol. 2013, 41, 45-48. [CrossRef] [PubMed]

108. Driscoll, K.E.; Carter, J.M.; Howard, B.W.; Hassenbein, D.G.; Pepelko, W.; Baggs, R.B.; Oberdörster, G. Pulmonary Inflammatory, Chemokine, and Mutagenic Responses in Rats after Subchronic Inhalation of Carbon Black. Toxicol. Appl. Pharmacol. 1996, 136, 372-380. [CrossRef] [PubMed]

109. Rittinghausen, S.; Bellmann, B.; Creutzenberg, O.; Ernst, H.; Kolling, A.; Mangelsdorf, I.; Kellner, R.; Beneke, S.; Ziemann, C. Evaluation of immunohistochemical markers to detect the genotoxic mode of action of fine and ultrafine dusts in rat lungs. Toxicology 2013,303, 177-186. [CrossRef]

110. Kyjovska, Z.O.; Jacobsen, N.R.; Saber, A.T.; Bengtson, S.; Jackson, P.; Wallin, H.; Vogel, U. DNA damage following pulmonary exposure by instillation to low doses of carbon black (Printex 90) nanoparticles in mice. Environ. Mol. Mutagen. 2015, 56, 41-49. [CrossRef]

111. Bourdon, J.A.; Saber, A.T.; Halappanavar, S.; Jackson, P.A.; Wu, D.; Hougaard, K.S.; Jacobsen, N.R.; Williams, A.; Vogel, U.; Wallin, H.; et al. Carbon black nanoparticle intratracheal installation results in large and sustained changes in the expression of miR-135b in mouse lung. Environ. Mol. Mutagen. 2012, 53, 462-468. [CrossRef] [PubMed]

112. Li, Z.; Hulderman, T.; Salmen, R.; Chapman, R.; Leonard, S.S.; Young, S.H.; Shvedova, A.; Luster, M.I.; Simeonova, P.P. Cardiovascular effects of pulmonary exposure to single-wall carbon nanotubes. Environ. Health Perspect. 2007, 115, 377-382. [CrossRef] [PubMed] 
113. Takagi, A.; Hirose, A.; Nishimura, T.; Fukumori, N.; Ogata, A.; Ohashi, N.; Kitajima, S.; Kanno, J. Induction of mesothelioma in $553+/-$ mouse by intraperitoneal application of multi-wall carbon nanotube. J. Toxicol. Sci. 2008, 33, 105-116. [CrossRef] [PubMed]

114. Yamaguchi, A.; Fujitani, T.; Ohyama, K.I.; Nakae, D.; Hirose, A.; Nishimura, T.; Ogata, A. Effects of sustained stimulation with multi-wall carbon nanotubes on immune and inflammatory responses in mice. J. Toxicol. Sci. 2012, 37, 177-189. [CrossRef] [PubMed]

(C) 2019 by the authors. Licensee MDPI, Basel, Switzerland. This article is an open access article distributed under the terms and conditions of the Creative Commons Attribution (CC BY) license (http://creativecommons.org/licenses/by/4.0/). 